Cómo citar este artículo / How to cite this article: Filipe, V. (2021). Las ánforas vinarias alto-imperiales de Lusitania: estado de la cuestión. Lucentum, XL, 197-214. https://doi.org/10.14198/LVCENTVM.18135

\title{
LAS ÁNFORAS VINARIAS ALTO-IMPERIALES DE LUSITANIA: ESTADO DE LA CUESTIÓN
}

THE EARLY-IMPERIAL WINE AMPHORAE FROM LUSITANIA: STATE OF THE QUESTION

VICTOR FILIPE

Centro de Arqueologia da Universidade de Lisboa (UNIARQ), Portugal

victor.filipe7@gmail.com https://orcid.org/0000-0003-4356-5442

Recepción: 08/11/2020

Aceptación: 05/02/2021

\section{Resumen}

La producción y comercialización del vino de la Lusitania romana sigue siendo un tema poco conocido y desarrollado en los estudios arqueológicos, principalmente debido a la escasa expresividad de los datos hoy disponibles. Por esta razón, su papel en la economía regional suele ser infravalorado. Mediante el análisis y la sistematización de datos antiguos y recientes referidos a los recipientes anfóricos destinados a transportar el vino producido en Lusitania, se pretende demostrar que la explotación vinícola en los valles de los ríos Tajo y Sado desempeñó un papel muy importante en la economía regional, en particular entre los siglos II y la mitad del siglo III d. C.

Palabras clave. Lusitania; economía romana; comercio; vino; consumo.

\begin{abstract}
The production and commercialization of wine in Roman Lusitania remains a poorly known and underdeveloped subject in archaeological studies, mainly due to the scarcity of data. For this reason, its role in the regional economy is usually neglected. Through the analysis and systematization of old and new data concerning the amphorae that transported Lusitanian wine, it is sought to prove that wine production in the Tagus and Sado river valleys played a significant role in the regional economy, particularly between the 2 nd and the first half of the $3^{\text {rd }}$ century AD.
\end{abstract}

Key words. Lusitania; Roman economy; trade; wine; consumption. 


\section{INTRODUCCIÓN}

En el marco de la producción y exportación de productos alimenticios transportados en ánforas en la época romana, Lusitania es conocida principalmente por sus salazones de pescado. La explotación de los recursos marinos y fluviales ha marcado en gran medida la economía de las regiones costeras de la provincia y la de los valles de sus grandes ríos, dando lugar a una importante actividad de procesamiento de pescado, que habría sido la marca industrial más visible. Aunque en gran medida destinada a abastecer a la propia provincia, esta industria también ha abastecido a los mercados de otras partes del Imperio, en particular del Mediterráneo occidental, donde están bien atestiguados los contenedores lusitanos destinados al transporte de estos productos.

Pero las ánforas lusitanas no sólo se utilizaban para el transporte de salazones de pescado, sino también para transportar el vino producido en diversas regiones de la provincia. La producción y exportación de este artículo en Lusitania, aunque innegable, es todavía un tema poco estudiado y mal definido en todos sus matices (Fabião, 1998; Mateo Corredor, 2016; Pereira, 2017).

A través de la referencia de Estrabón (III, 3, 1) se sabe que en una fase muy temprana de la presencia romana en el oeste peninsular (siglo II a. C.), existían en el Valle del Tajo «hermosos viñedos». Sin embargo, quedan por sistematizar los datos relativos a las estructuras de producción de vino conocidas en Lusitania (Bustamante Álvarez y Cordero Ruiz, 2013). Además, no siempre es fácil distinguir a partir de los restos arqueológicos los lagares de vino de las almazaras de aceite (Brun, 2020: 4; Cervantes, 2020: 74) 一véase el caso de la villa romana de Freiria (Cardoso, 2015: 133) - y el instrumental agrícola suele ser lo suficientemente versátil como para poder deducir a partir de él una dedicación exclusiva a la viticultura. Por otra parte, las representaciones iconográficas de motivos relacionados con la vid o con las actividades de vendimia, no corresponden necesariamente a evidencias de la producción vitivinícola local, ya que se trata de «temas recurrentes, relacionados con el universo simbólico de las sociedades» productoras de vino (Fabião, 1998: 171). Asimismo, los tituli picti conocidos sobre ánforas lusitanas se documentan exclusivamente en contenedores piscícolas (Djaoui y Quaresma, 2016; Quaresma, 2018). También faltan resultados de estudios arqueométricos sobre residuos de vino en ánforas de producción lusitana, los datos paleobotánicos son exiguos y no nos han llegado restos de odres o toneles en esta provincia, a pesar de la inspiración directa que algunos monumentos funerarios tuvieron en estos últimos. En el caso de los dolia, no siempre es posible

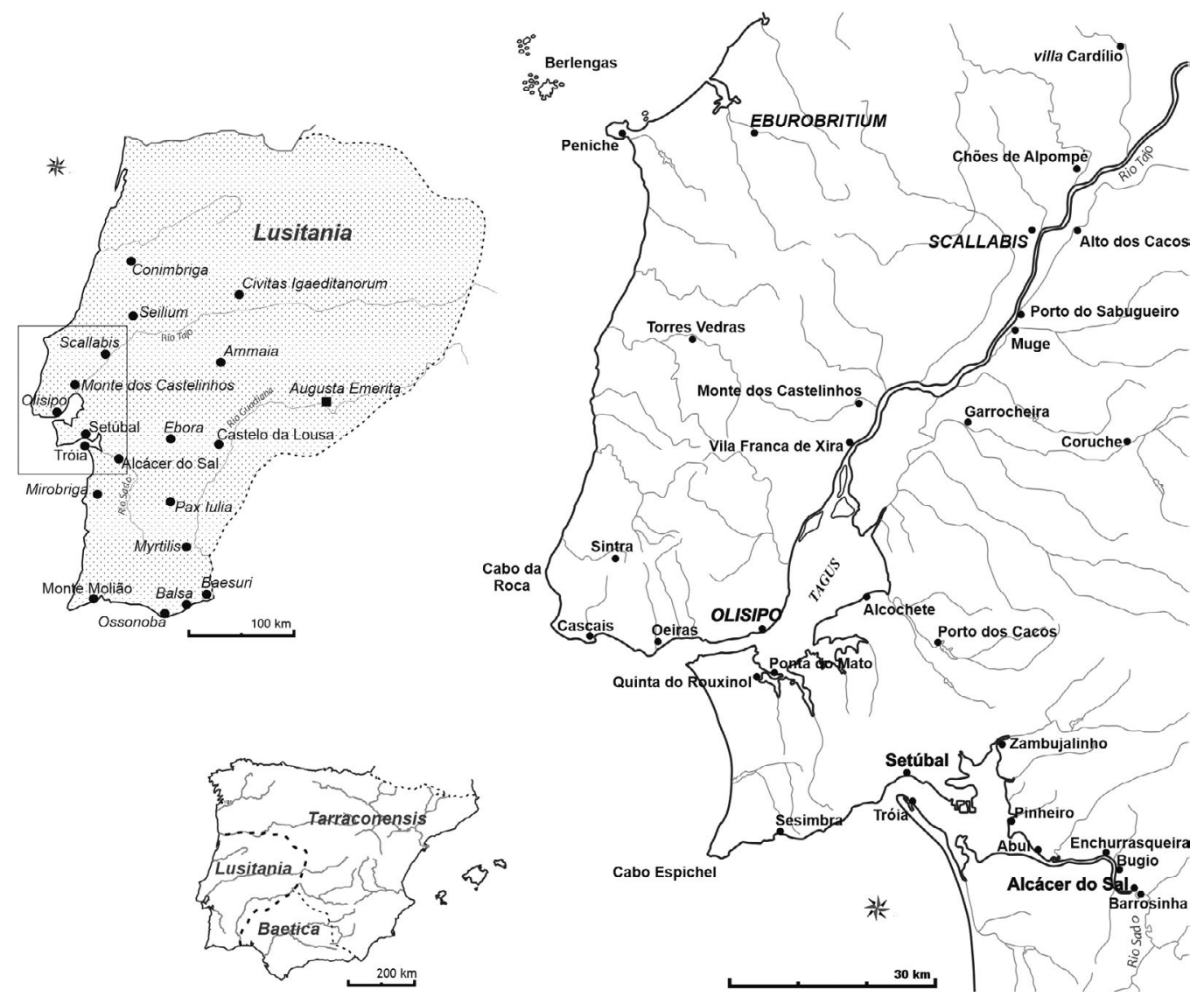

Figura 1: Provincia romana de Lusitania y valles de los ríos Tajo y Sado, con ubicación de algunos de los principales yacimientos mencionados en el texto 
establecer una relación directa entre su presencia y su uso en el proceso de elaboración o almacenamiento del vino, ya que se prestaban a diferentes usos.

En este contexto, el estudio de las ánforas vinarias lusitanas constituye una de las principales fuentes de información disponibles sobre la producción de vino en Lusitania (Fig. 1). Sin embargo, también en este campo de la investigación los conocimientos actuales siguen siendo escasos y parciales. El carácter disperso de la información y la reciente publicación de nuevos e importantes datos justifican este estudio. El objetivo es recoger, sintetizar y sistematizar dicha información, discutiendo su significado y abordando aspectos cruciales acerca de su producción - especialmente en los valles de los ríos Tajo y Sado-, su peso en la economía local y su alcance en el marco del comercio del vino envasado en ánforas durante el Alto-Imperio. Sólo recientemente, con la publicación de nuevos datos, se ha demostrado que, si bien su alcance parece haber sido predominantemente regional, el comercio del vino producido en Lusitania también habría llegado a otras regiones del Imperio Romano. La definición de la escala y el alcance geográfico de esas exportaciones es de particular importancia.

El ánfora vinaria lusitana de mayor éxito fue, sin duda, la Lusitana 3, siendo igualmente la forma mejor estudiada. Además, en el Alto-Imperio se produjeron otras ánforas vinarias, a saber, las imitaciones de Haltern 70, de Dressel 28, de Dressel 2-4 y de ánforas del tipo Urceus, esta última sólo recientemente individualizada (Filipe, 2019). Todas estas formas todavía no están suficientemente caracterizadas. En cuanto a su cronología, cabe destacar también que, si bien la Haltern 70 comienza a fabricarse en la fase final de la República y la Lusitana 3 se prolonga hasta mediados de siglo III d. C., ambos tipos se producen y comercializan principalmente durante el Alto Imperio, por lo que se justifica su inclusión en este trabajo. Los tipos vinarios de época tardía, como la Lusitana 9 y los probables casos de las Rouxinol 35 y Sado 4, no se han incluido en este estudio.

En la primera parte de este trabajo se presenta la caracterización de cada uno de estos tipos en cuanto a su morfología, contenido, alcance cronológico, centros de producción y radio de difusión. A continuación se discute y problematiza el significado de estas producciones y su comercialización provincial y extra-provincial.

\section{2. ÁNFORAS VINARIAS LUSITANAS: NUEVOS Y VIEJOS DATOS}

\subsection{HALTERN 70 LUSITANA}

La producción en Lusitania de Haltern 70 fue identificada recientemente por Rui Morais (2004). En este estudio, el autor presentó un significativo conjunto de contenedores de clara producción lusitana, exhumados en contextos de la segunda mitad del siglo I a. C. y procedentes de diversos lugares del noroeste peninsular y del Castelo da Lousa, en el Alentejo, destacando los tipos de morfología ovoide y los análogos a la Haltern 70 (Morais, 2004; Morais y Fabião, 2007). En los años siguientes se publicaron nuevos datos a partir de los hallazgos del río Tajo, Vila Franca de Xira (Quaresma, 2005), Ilha da Berlenga (Diogo et al., 2005), Santarém (Arruda et al., 2006), Alcácer do Sal (Pimenta et al., 2006) y Lisboa (Filipe, 2008; 2015).

Las imitaciones lusitanas de Haltern 70 se identifican a menudo en la literatura arqueológica con diferentes clasificaciones, o bien incluidas en designaciones que integran un conjunto más amplio de formas, como las «Ovoides lusitanas» (Morais, 2004; Filipe, 2008; 2015), las «Lusitanas Antigas» (García Vargas et al., 2011; Filipe, 2019) y las «Lusitana precoce» (Morais, 2010), o individualizadas y clasificadas como «afins à Haltern 70» o simplemente Haltern 70 lusitana (Quaresma, 2005; 2018; Arruda et al., 2006; Filipe, 2016; Almeida y Fabião, 2019).

En lo que respecta a sus características morfológicas, la Haltern 70 lusitana es generalmente idéntica a sus homólogas béticas: borde liso al exterior, cuello cilíndrico o bitroncocónico, asas de sección ovalada y acanaladura en la cara exterior, hombro caído y suavemente carenado y cuerpo ovoide o cilíndrico, rematado en un fondo cónico macizo. Sólo se conocen tres ejemplares completos o semi-completos: en río Tajo (Quaresma, 2005: fig. 3), Ilha da Berlenga (Diogo et al., 2005: fig. 5) y Arles (Quaresma, 2018: 202), todos de procedencia subacuática. Lamentablemente, y a pesar de estas excepciones, la mayoría de los ejemplares conocidos de Haltern 70 lusitana consisten en pequeños fragmentos de borde o de fondo, mayoritariamente descontextualizados. Esta situación constituye un obstáculo para la caracterización de una evolución más que probable del tipo a lo largo del período en que se produjo — reflejada en variaciones morfológicascomo ya se ha hecho para el Valle del Guadalquivir (Berni Millet, 2011).

La circulación de la Haltern 70 lusitana está atestiguada desde el tercer cuarto del siglo I a. C. por hallazgos como los de Monte dos Castelinhos (Pimenta, 2017), Castelo da Lousa (Morais, 2004; 2010; Morais y Fabião, 2007) y Pedrão (Mayet y Silva, 2016) (Fig. 2). Es decir, su producción se habría iniciado unos años después de la aparición de la Haltern 70 en el Valle del Guadalquivir, cuyos primeros ejemplares se documentan, según algunos autores, a mediados del siglo I a. C. (Berni Millet, 2011). Sin embargo, en lo que respecta a estos ejemplares más antiguos, hay que preguntarse si no representarían más bien imitaciones de otro tipo de Valle del Guadalquivir: la Ovoide 4. Esto nos lo sugiere no sólo su cronología antigua y posiblemente demasiado cercana a la de la fase inicial de la bética Haltern 70, sino también otro tipo de evidencias: la reducida altura de los bordes de algunas de estas piezas lusitanas, característica atribuible a la Ovoide 4; la producción atestiguada en el Valle del río Tajo y/o 


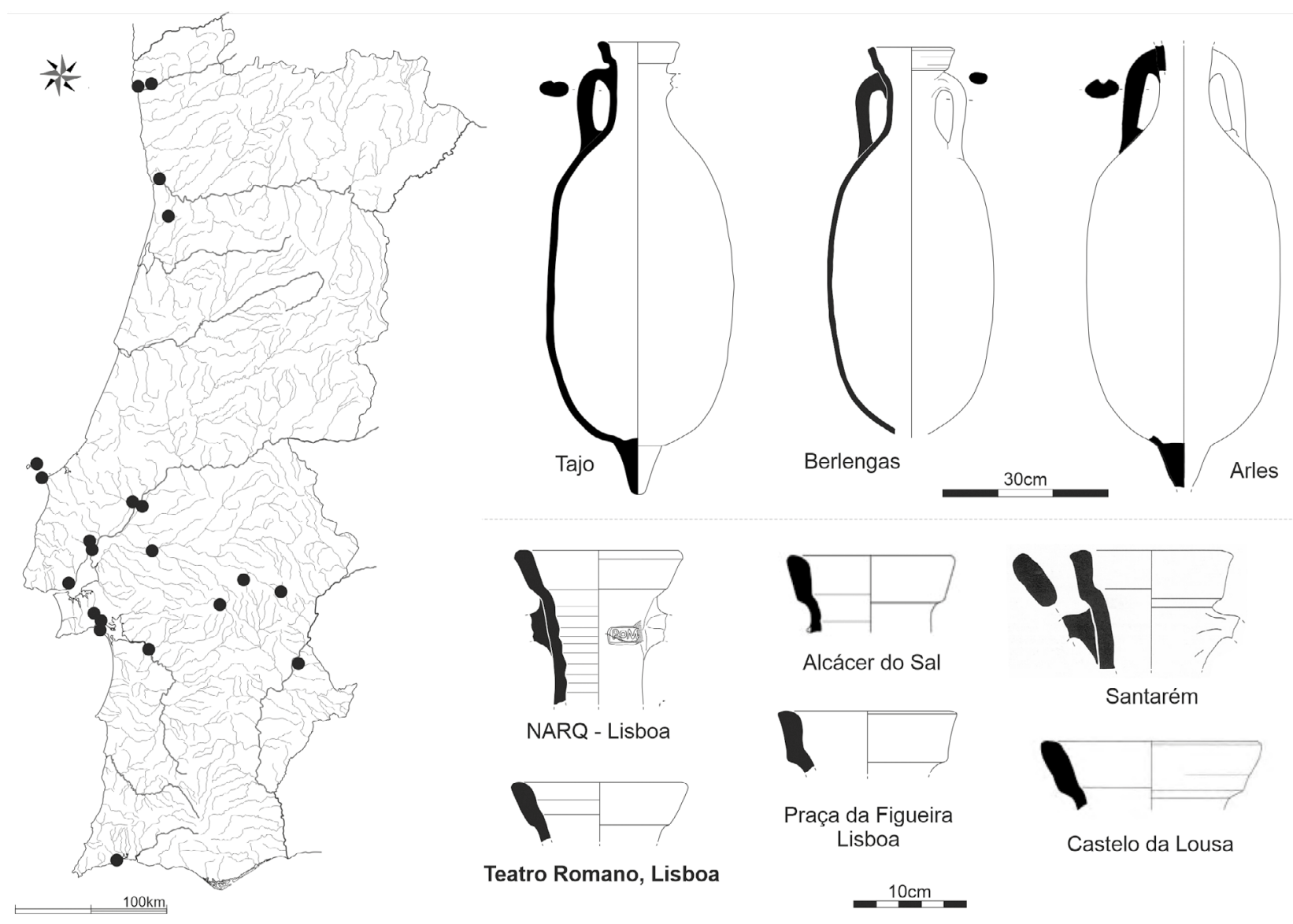

Figura 2: Haltern 70 lusitana: difusión en el territorio portugués y ejemplares completos y fragmentados

Sado, durante el tercer cuarto del siglo I a. C., de otras imitaciones tempranas de ovoides del Guadalquivir, en especial la Ovoide 1/Clase 67; sin olvidar el hecho de que algunos autores datan el inicio de las Haltern 70 del Guadalquivir hacia 30 a. C., encuadrando las formas anteriores en las Ovoide 4 (García Vargas et $a l ., 2011)$. Desde este punto de vista, se podría considerar para las producciones del extremo occidental una evolución tipológica idéntica a la que se produjo entre la Ovoide 4 y Haltern 70 del Valle del Guadalquivir. Naturalmente, esta es una hipótesis que necesitará confirmación futura.

Es principalmente a partir de Augusto cuando la Haltern 70 lusitana está claramente documentada, compareciendo, además de los lugares ya mencionados, en varios sitios del noroeste peninsular (Morais, 2004; Morais y Fabião, 2007), Santarém (Arruda et al., 2006), Caladinho (Mataloto et al., 2016), Setúbal (Mayet y Silva, 2016) y Lisboa (Filipe, 2019; 2020). Se halla bien atestiguada en contextos de la primera mitad del siglo I d. C., por ejemplo, en Santarém (Arruda et al., 2006), Lisboa (Filipe, 2008; 2015; 2019), Tróia (Pinto et al., 2011) y Monte Molião (Arruda y Viegas, 2016). La cronología del fin de su producción sigue abierta. Sin embargo, teniendo en cuenta su presencia en los contextos flavios en Zara/Rua Augusta, Lisboa (Filipe, 2019), aunque escasamente representada, se puede considerar que su fabricación se prolonga hasta ese momento, igual que ocurre con las producciones béticas del mismo tipo y con el resto de las Lusitanas Antiguas. La publicación futura de un mayor volumen de datos contextuales debería confirmar o refutar esta hipótesis.

La producción de imitaciones de Haltern 70 en Lusitania está atestiguada en varias regiones, lo que es una clara evidencia del éxito que alcanzó este contenedor en el Occidente de la Península, como también se comprueba para las imitaciones producidas en diferentes lugares de la costa bética (Carreras Monfort, 2016) y de la Galia (Desbat y Dangreaux, 1992). Parece haber sido producida en el centro alfarero de la Rua António Joaquim Granjo, Setúbal, en el período augusteo (Mayet y Silva, 2016). Aunque no se han identificado los hornos, se documentó la presencia de varias piezas con defectos de cocción encuadrables tipológicamente dentro de las primeras producciones lusitanas. Puede haber sido fabricada en Alcácer do Sal, en los Fornos da Parvoíce (Pimenta et al., 2016). También se puede mencionar el centro alfarero de Morraçal da Ajuda, Peniche, donde se produjo entre los principados de Augusto y Claudio la llamada Peniche 2, similar a la Haltern 70 (Cardoso et al., 2016). Asimismo, en Monte Molião se han identificado recientemente evidencias de una producción de Haltern 70 atribuible a un centro productor no localizado del Algarve, con una cronología encuadrable entre Augusto y Calígula (Arruda y 
Viegas, 2016). Finalmente, cabe mencionar la producción de Haltern 70 en Augusta Emerita (Alba Calzado y Méndez Grande, 2005; Bustamante Álvarez y Heras Mora, 2013; 2016).

Sin embargo, parece bastante claro que una parte importante de las alfarerías que fabricaban la Haltern 70 en Lusitania sigue siendo desconocida. La posibilidad de que exista una producción en los valles del Tajo y del Sado se basa, por una parte, en el hecho de que en varios centros de consumo se han documentado Haltern 70 lusitanas y otros tipos tempranos lusitanos cuyas características químicas y petrográficas no coinciden con las de los centros productores conocidos (Fabião, 2008; Filipe, 2016; Almeida y Fabião, 2019). Esto se verificó, por ejemplo, en Santarém (Arruda et al., 2006: 237), Castelo da Lousa (Morais y Fabião, 2007: 129; Morais, 2010: 191), y Lisboa (Dias et al., 2012: 68; Filipe, 2015: 78; 2019). Por otra parte, las producciones de Augusta Emerita y de Algarve sólo se conocen en la capital de la provincia y en Monte Molião respectivamente, mientras que las de Peniche tuvieron una difusión relativamente limitada en términos cuantitativos, siendo, además, distinguibles de la del Tajo/Sado. De hecho, en los conjuntos publicados hasta ahora, las producciones de Peniche o están ausentes o son francamente minoritarias, de modo que todo parece indicar que la gran mayoría de las piezas de dichos conjuntos provienen de alfarerías ubicadas en los valles de los ríos Tajo y Sado.

La cuestión del contenido de la Haltern 70 lusitana sigue abierta, sin que aún haya evidencias directas. Por lo tanto, su consideración como contenedor de vino carece de base empírica, lo que, por otra parte, también sucede con el resto de las formas anfóricas analizadas en este trabajo. Aun así, asumimos un contenido vinario, basado en argumentos más o menos obvios, que deben ser necesariamente confirmados en el futuro. En primer lugar, porque se trata de una imitación de un contenedor destinado a transportar vino o derivados. Por otra parte, porque ya en el siglo II a. C. Estrabón (III, 3,1 .) menciona la existencia de la vid en el Valle del Tajo. Esta referencia constituye la clara demostración de la existencia de una tradición vitivinícola en esta región, que probablemente debería remontarse a momentos aún anteriores a la presencia romana. Pero también cabe mencionar la existencia de otras ánforas vinarias, analizadas en este trabajo, y, sobre todo, la Lusitana 3 que surge en el siglo. II d. C. en grandes proporciones.

Como se ha expuesto, la Haltern 70 lusitana alcanzó prácticamente todo el territorio provincial, extendiéndose igualmente al noroeste de la Tarraconense. Los hallazgos se concentran principalmente en esta última región, en los valles de los ríos Tajo y Sado y en el interior del Alentejo, observándose, por el contrario, una presencia escasa de este tipo en el Algarve. Aunque posiblemente este hecho pueda relacionarse con la mayor dependencia de este último territorio con respecto a la Bahía de Cádiz durante los primeros siglos de nuestra Era (Viegas, 2011: 206), esta escasez es particularmente sorprendente a la luz de la reciente propuesta de una producción regional de Haltern 70 (Arruda y Viegas, 2016). Especialmente ilustrativa del radio de difusión que habrían alcanzado estas imitaciones lusitanas es la presencia de un ejemplar casi completo, de fabricación Tajo/Sado, en Arles (Djaoui y Quaresma, 2016: 359; Quaresma, 2018: 202).

Por último, hay que mencionar la única marca conocida sobre uno de estos contenedores. Procedente del NARQ, Lisboa, conserva el borde, el cuello y las asas. El sello se sitúa en el cuello y se encuentra incompleto en su parte final, estando inscrito en una cartela rectangular donde se puede leer ROM[...] o POM[...] (Dias et al., 2012: 61, fig. 2, n. ${ }^{\circ}$ 3460; Fabião et al., 2016: 109 y Est. 14, n. $\left.^{\circ} 131\right)$.

\section{2. ÁNFORAS DE TIPO URCEUS LUSITANAS}

Recientemente, se han identificado en varios lugares de la ciudad de Lisboa algunos bordes de ánfora de difícil clasificación con las típicas pastas lusitanas (Filipe, 2019: 364-367). Sus características morfológicas no se ajustan a ninguno de los tipos conocidos hasta ahora en el repertorio de la provincia. El mal estado de conservación de esos ejemplares, en su mayoría pequeños fragmentos de borde y de fondo, plantea algunas dificultades para su correcta caracterización. Aun así, los datos disponibles parecen ser suficientes para afirmar que estamos ante una forma producida en Lusitania hasta ahora desconocida: las ánforas del tipo Urceus. Esta forma de fondo plano, recientemente individualizada por Rui Morais $(2005 ; 2008)$, es originaria de la costa bética y del Valle del Guadalquivir, y fue fabricada entre el comienzo del principado de Augusto y mediados del siglo I d. C. (Morais, 2008: 269; García Vargas et al., 2011: 250).

Las piezas mencionadas tienen, en general, bordes que no sobresalen de la pared del cuello, sino que sólo están engrosados en el interior, redondeados y ligeramente reentrantes, siendo la superficie exterior ligeramente convexa. Las paredes del cuello no son muy gruesas, con un perfil troncocónico o estrangulado en la mitad inferior. La superficie externa puede ser lisa o tener un acanalado horizontal, más o menos marcado. Sólo una de las piezas conserva el inicio del asa, pero no es posible saber cómo sería su sección y cómo se desarrollaría el perfil. El arranque superior del asa está a 3,4 cm de la parte superior del borde. La mayoría de los ejemplares tiene un engobe de color crema en la superficie externa, mientras que en la pieza del Teatro Romano se aplicó un fino engobe blanco en la superficie interna. El diámetro de estos bordes varía entre 14 y $19 \mathrm{~cm}$. En la pasta se observan sobre todo cuarzos redondeados y angulares, algunos óxidos de hierro y mica.

Aunque no se encuadren en ninguna de las formas conocidas en Lusitania, las características morfológicas 

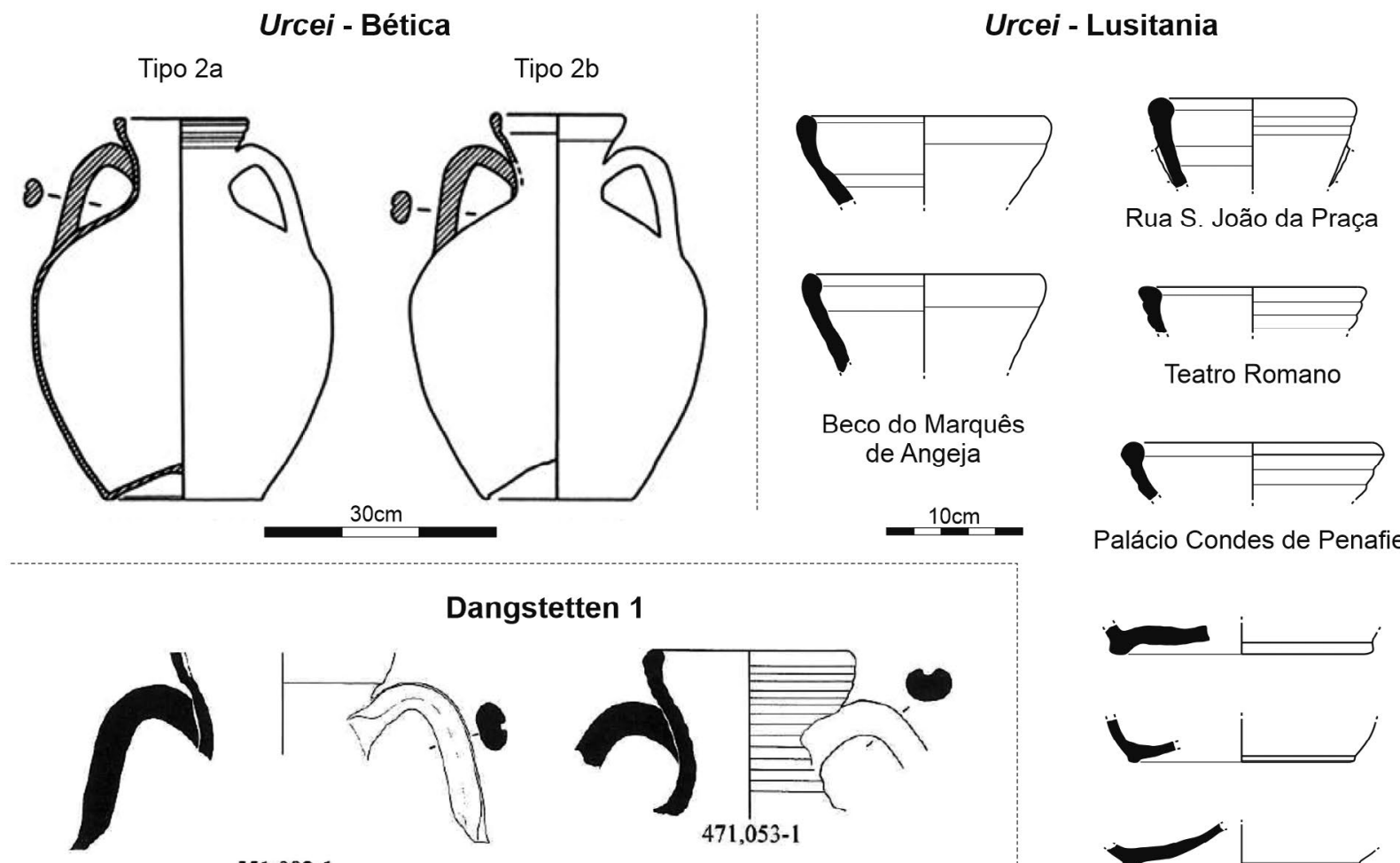

angstetten 1
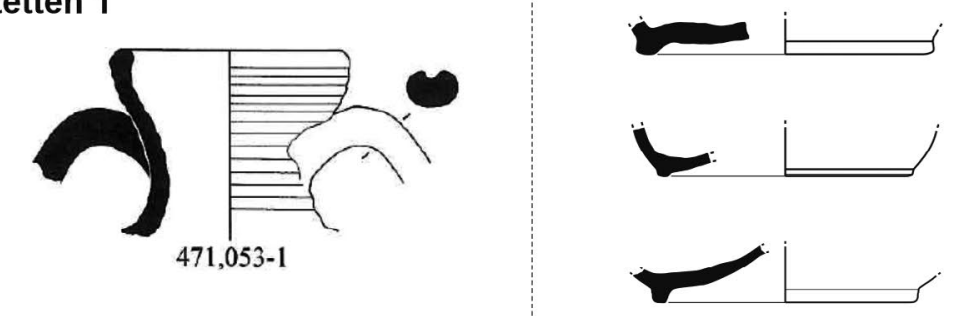

Rua dos Bacalhoeiros

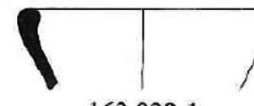

$163,028-1$

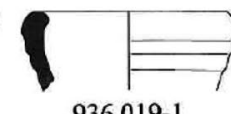

936,019-1

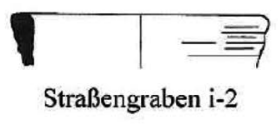

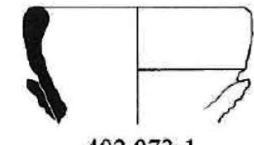

402,073-1

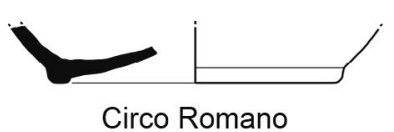

Figura 3: Urcei de tipo 2a y 2b de la Bética (arriba), ejemplares de tipo 2 de Dangstetten (abajo) y Urcei de fabricación lusitana (derecha)

de estas piezas encuentran paralelos bastante aproximados en las producciones béticas denominadas ánforas del tipo Urceus, concretamente en los tipos 2 y 3 de Morais (2008: fig. 2), que equivalen a los tipos 2a y 2b de García Vargas et al. (2011: fig. 31). También es sugerente el hecho de que en las piezas lusitanas haya ejemplares con superficie externa lisa y otros con estrías horizontales. Particularmente ilustrativas de estas similitudes formales son algunas ánforas del tipo Urceus 2a y $2 \mathrm{~b}$ documentadas en Dangstetten (Ehmig, 2010: taf. 32, n. $^{\circ} 471.053-1$, y taf. 33 , n. ${ }^{\circ} 163.028-1$ y 936.019-1). Además de las obvias afinidades morfológicas, hay que hacer referencia a la aparente contemporaneidad entre los ejemplares lusitanos y los contenedores de fondo plano de la Baetica (Fig. 3).

Hasta ahora sólo se han identificado cinco fragmentos de borde de este tipo, todos en Lisboa, procedentes de los siguientes lugares: Beco do Marquês de Angeja, donde se identificaron dos ejemplares en un contexto fechado entre el principado de Augusto y mediados del siglo I d. C. (Filipe y Calado, 2007: 5); Teatro Romano, un borde en un nivel posromano - cabe señalar que en este lugar la cronología de los abundantes materiales romanos no supera la mitad del siglo I d. C., aunque aparecen en cantidades importantes en contextos medievales (Filipe, 2015) -; Rua de São João da
Praça (intervención de 2009): un borde en un nivel aparentemente tardío; y Palácio dos Condes de Penafiel: un borde, sin indicaciones estratigráficas (Filipe, 2019).

Otro indicio importante de la producción lusitana de ánforas del tipo Urceus es la existencia de fondos planos de producción local/regional. Estos se atestiguan en los siguientes lugares: Rua dos Bacalhoeiros, Lisboa, cuatro fondos en contextos que datan de mediados del siglo I d. C. (Filipe, 2008; 2019); Circo Romano, Lisboa, un fondo recogido en un nivel de cronología imprecisa (Filipe, 2019); y Monte dos Castelinhos, Vila Franca de Xira, en contextos de Claudio (comunicación personal de João Pimenta, a quien se la agradecemos). Sin embargo, en el caso de los fondos planos, su atribución tipológica a las ánforas del tipo Urceus es menos segura, ya que se confunden fácilmente con los fondos de Dressel 28, también producidos en Lusitania. Esta dificultad se agrava por la indefinición de la cronología de las imitaciones de Dressel 28.

Dada su total ausencia en las publicaciones, seguramente sería una producción minoritaria y de escasa difusión. Sin embargo, hay que tener en cuenta que, como durante mucho tiempo fue el caso de las ánforas béticas de tipo Urceus, su «apariencia» de cerámica común podría explicar esta ausencia. Cabe señalar también que, al parecer, esta forma no se encuentra en 
los centros alfareros lusitanos conocidos. Pero, a este respecto, hay que recordar que también para la mayoría de las Lusitanas Antiguas y Haltern 70 lusitanas se desconocen los centros alfareros (Dias et al., 2012; Filipe, 2016; 2020).

Aunque todavía incompletos, los datos expuestos parecen ser suficientes para proponer una producción de ánforas de tipo Urceus en los valles de los ríos Tajo y Sado durante la primera mitad del siglo I d. C. Por analogía directa con sus homónimas béticas, es muy probable que se destinasen a transportar vino.

\section{3. «DRESSEL 2-4» LUSITANA}

Aunque han pasado 30 años desde la primera publicación en la que se mencionaba la imitación de Dressel 2-4 en Lusitania (Cardoso, 1990), las noticias sobre estas producciones han faltado casi completamente hasta hoy. La forma no está representada en la tipología de Dias Diogo (1987), de la misma manera que no se considera en las síntesis sobre las producciones lusitanas (Fabião, 2008).

En 1988 se presentó «O forno de ânforas de Muge», donde se hace referencia a Dressel 2-4, junto con otras formas como las Lusitanas Antigas y la Dressel 14 (Fig. 4). Aunque alude a la existencia de otros dos fragmentos atribuibles a Dressel 2-4, entre ellos un hombro carenado, el autor presenta sólo el dibujo de una pieza que conserva todo el borde y el cuello, así como el inicio de unas asas cuya sección parece «ser de tipo cinta, con una acanaladura central en la parte exterior similar a las aplicadas a la forma de Dressel 14») (Cardoso, 1990: 156-158).

La morfología de esta pieza encaja bien con las características de la Dressel 2-4, presentando borde grueso y redondeado y cuello alto y cilíndrico, cuya transición al hombro parece estar marcada por una inflexión brusca (Cardoso, 1990: fig. 41, n. ${ }^{\circ}$ 1). Sin embargo, hay dos aspectos que parecen desentonar con los modelos itálicos. Por un lado, la inclinación del inicio de las asas, sólo sugerida por su mala conservación, recuerda a los modelos orientales Dressel 5 o, en menor medida, a los modelos Dressel 3. Por otra parte, parece tener dimensiones algo reducidas, especialmente cuando se compara con las piezas 3 a 6 de la misma imagen. En relación, igualmente, con los contextos arqueológicos del centro alfarero de Muge, se registró la presencia de cerámica con defectos de cocción, donde se incluyen fragmentos de ánfora. Sin embargo, no se han documentado los hornos que habrían producido estos contenedores (Cardoso, 1990: 154-157).

Sobre la cronología, el autor indica que «se sitúa predominantemente en la época de las dinastías Flavia y Antonina» (Cardoso, 1990: 158). Sin embargo, habrá que remontar el inicio de su actividad al menos hasta la primera mitad del siglo I d. C., teniendo en cuenta la fabricación de ánforas de morfología antigua en el taller, cuya producción no superó la dinastía Flavia (Filipe, 2019; 2020). A pesar de estas limitaciones, este lapso de tiempo, que se extiende aproximadamente desde la primera mitad del siglo I d. C. hasta la segunda mitad del siglo II d. C. es, por el momento, el mejor indicador de la cronología de producción de la imitación de Dressel 2-4 en Lusitania.

Además del centro alfarero de Muge, estas imitaciones sólo están atestiguadas en Augusta Emerita (Almeida y Sánchez Hidalgo, 2013) y Felicitas Iulia Olisipo (Filipe, 2019). En la capital provincial se conocen cuatro piezas en el Cuartel de Hernán Cortés con fabricación atribuible a los valles de los ríos Tajo y Sado (Almeida y Sánchez Hidalgo, 2013: 50-54) y otros 10 de procedencia indeterminada en la Lusitania. En Olisipo, sólo se registró un fragmento de asa bífida del Tajo/Sado en las excavaciones de las Termas dos Cássios (Fig. 4), de la que se conservó uno de los bastones (Filipe, 2019: 342). En ambos casos, se desconoce la cronología del contexto de origen.

En cuanto al contenido, es muy probable que estuvieran destinadas a transportar vino.
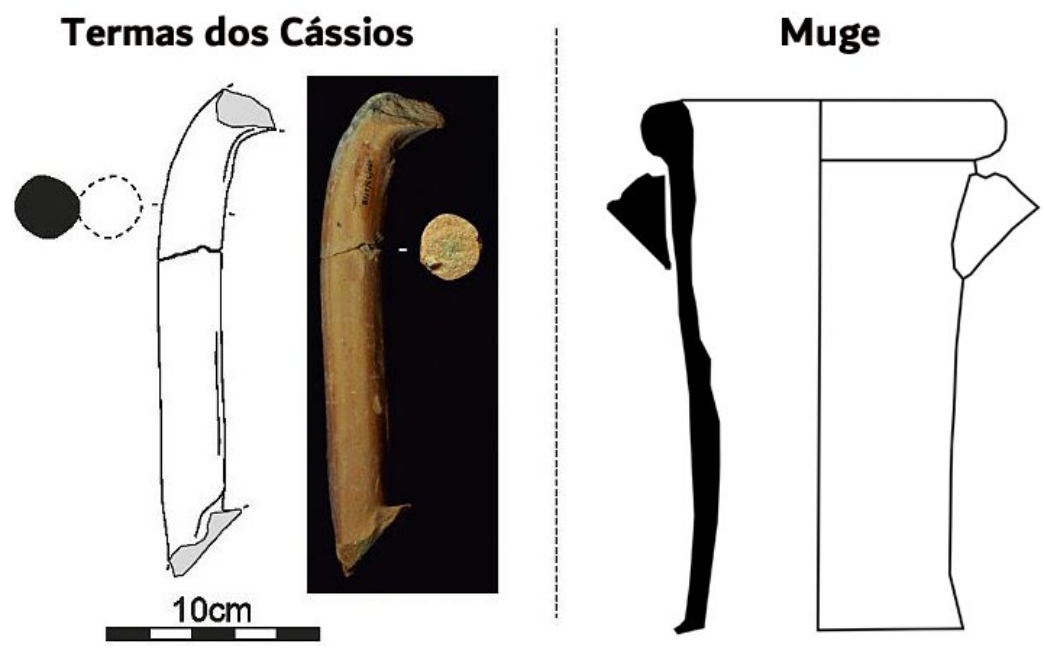

Figura 4: Dressel 2-4 de fabricación lusitana procedentes de las Termas dos Cássios, Lisboa, y de la alfarería de Muge 


\section{4. «DRESSEL 28»}

Aunque la producción de ánforas similares a la Dressel 28 está atestiguada desde hace mucho tiempo en Lusitania, nunca ha sido debidamente estudiada y caracterizada, en gran parte debido a su escasez en los centros de producción y de consumo. Se trata de una producción minoritaria de la que no se conocen ejemplares completos, con muy pocos datos contextuales y cronológicos (Fig. 5).

La referencia más antigua se remonta a 1986, con la publicación de una pieza recogida en la alfarería de Pinheiro, luego clasificada como Dressel 28/Oberaden 74 de fabricación local (Cardoso, 1986: 161 y Est. I, n. ${ }^{\circ}$ ). En 1990 se publican los primeros resultados de las excavaciones de la alfarería de Porto dos Cacos, donde se incluyen dos fragmentos de borde clasificados como Dressel 28 (Raposo, 1990: 127 y fig. 37, n. ${ }^{\circ}$ 89-90). Algunos años después, se publica la monografía del centro alfarero de Pinheiro, donde se presentan algunas piezas de producción local clasificadas como Dressel 28, así como otras morfológicamente similares a la Oberaden 74 (Mayet y Silva, 1998: 123 y 135).

Al mismo tiempo, Dias Diogo se refiere a la producción de Dressel 28 en el Valle del Sado (Diogo, 1987: 185), publicando más tarde algunos ejemplares de villa
Cardílio, Torres Novas (Diogo y Monteiro, 1999: 204 y Est. IV, n. ${ }^{\circ} 32$ y 33) y Tróia (Diogo y Paixão, 2001: 125 y fig. 6, n. $\left.{ }^{\circ} 27\right)$. Dias Diogo denominó a este tipo Lusitana 14 (Diogo, 1999: 18), y lo fecha entre mediados del siglo I d. C. y finales del siglo II (Diogo y Monteiro, 1999: 204), basándose principalmente en la cronología de la Dressel 28 bética (Diogo y Paixão, 2001: 118).

Además de los centros productores ya mencionados, estas formas fueron atestiguadas en Olisipo (Filipe, 2019: 357-362), villa de Freiria (Cardoso, 2015: fig. 246, n. ${ }^{\circ}$ 102), Tróia (Diogo y Paixão, 2001: 125 y fig. 6, n. ${ }^{\circ}$ 27), villa Cardílio (Diogo y Monteiro, 1999: 204 y Est. IV, n. ${ }^{\circ} 32$ y 33), Herdade do Reguengo, Monforte (Diogo, 1999-2000: 313 y fig. 2, n. 3), Conimbriga (Buraca, 2005: 32) y Seilium (Prudêncio et al., 2005: fig. 7).

La Dressel 28 fue producida en las provincias de la Bética, Tarraconense y Narbonense, constituyendo uno de los recipientes de fondo plano más antiguos para el transporte de vino (García Vargas et al., 2011).

$\mathrm{Su}$ producción en la Bética se centra principalmente entre principios del siglo I d. C. y mediados del siglo siguiente, aunque se prolongue hasta principios del siglo III (García Vargas, 2015). Sin embargo, los escasos datos estratigráficos documentados para las
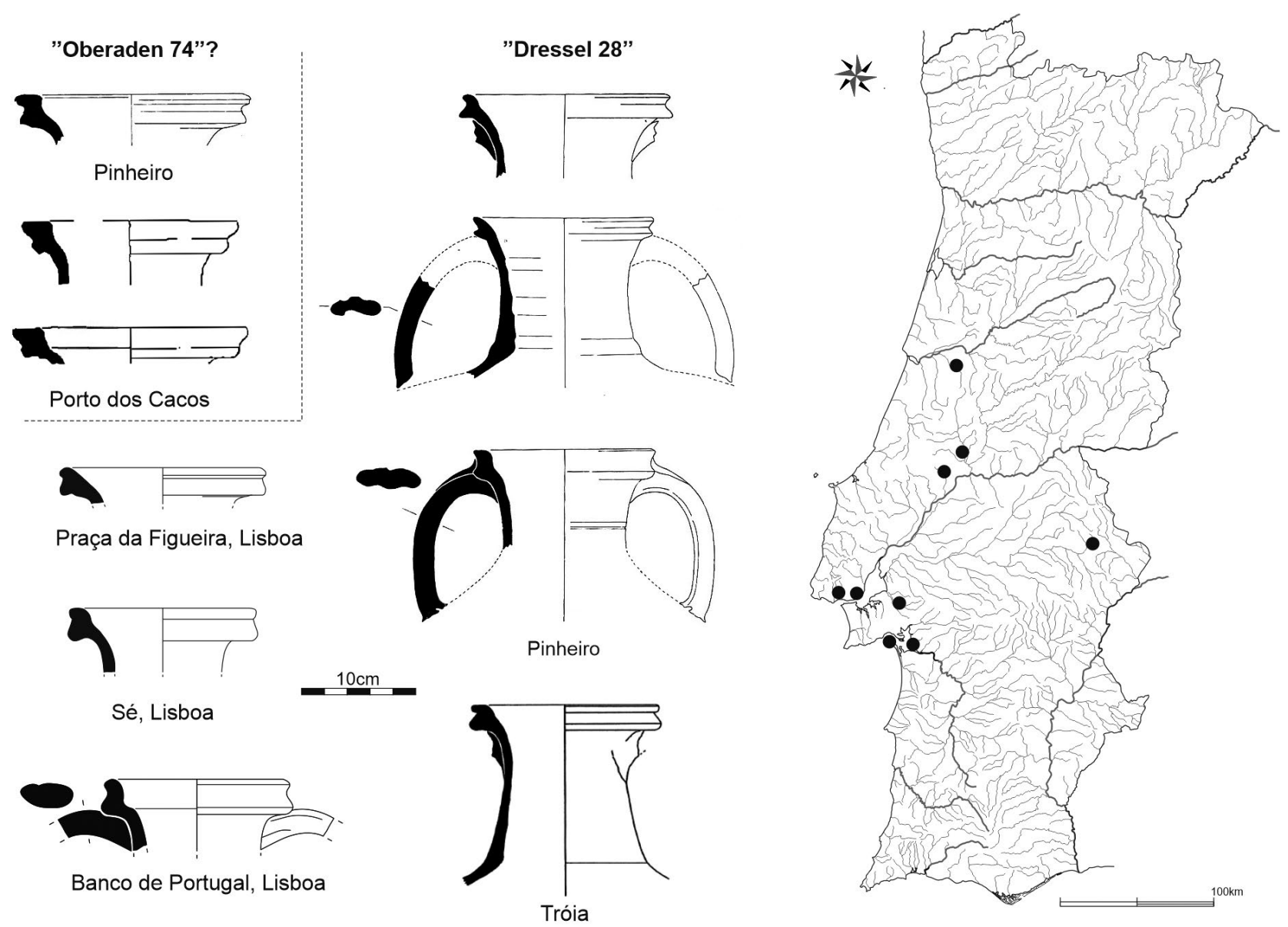

Figura 5: Ejemplares de «Dressel 28» y variantes similares a las Oberaden 74 de fabricación lusitana y su difusión en el territorio portugués 
producciones lusitanas parecen apuntar principalmente a fechas posteriores. En Pinheiro y Porto dos Cacos, la cronología de algunas de estas formas parece centrarse en el final del siglo II d. C. y la primera mitad del III (Mayet y Silva, 1998: 123; Fabião, 2008: 735). También en lo que respecta a los centros de consumo los datos cronológicos disponibles son muy escasos. En Conimbriga se registran en niveles de Trajano (Buraca, 2005: 32) y en la Rua dos Bacalhoeiros, Lisboa, los fragmentos de fondo proceden de contextos de mediados del siglo I d. C. (Filipe, 2008; 2019). Pero, en el caso de estos últimos, hay que tener en cuenta que es más probable que sean fondos de ánforas del tipo Urceus.

La diversidad de perfiles de borde en los ejemplares mencionados no permite aclarar si ello se debe a la existencia de diferentes variantes o si, por el contrario, puede indicar la existencia de otros tipos. Sea como sea, los ejemplares que se enmarcan aquí en la «Dressel 28» lusitana y que pueden considerarse más cercanos a la Dressel 28 bética, presentan bordes con diámetros que varían entre 15 y $19 \mathrm{~cm}$, y incluyen, por ejemplo, las producciones de la alfarería de Pinheiro (Mayet y Silva, 1998: 123 y 135), los ejemplares de Praça da Figueira, Banco de Portugal y Sé Catedral, todos de Lisboa (Filipe, 2019), de Seilium (Prudêncio et al., 2005: fig. 7), de Tróia (Diogo y Paixão, 2001: 125 y fig. 6, n. ${ }^{\circ}$ 27) y de la Herdade do Reguengo, Monforte (Diogo, 1999-2000: 313 y fig. 2, n. ${ }^{\text { } 3) . ~ P o r ~ o t r o, ~ s e ~ e n c u e n t r a n ~}$ los que están más cerca de la Oberaden 74 que incluyen algunas piezas de Porto dos Cacos (Raposo, 1990: 127 y fig. 37, n. $\left.{ }^{\circ} 89-90\right)$ y el ejemplar n. ${ }^{\circ} 76$ de la alfarería de Pinheiro (Mayet y Silva, 1998: 135, fig. 52), con diámetros que varían entre 16 y $19 \mathrm{~cm}$. En ambos casos, los datos cronológicos parecen apuntar hacia una datación distinta de sus homólogas béticas y tarraconenses.

En lo que respecta al producto transportado por estos contenedores, las similitudes con la Dressel 28 sugieren un contenido vinario (Diogo y Monteiro, 1999: 204; Fabião, 2008: 736).

\subsection{LUSITANA 3}

Individualizada por Dias Diogo (1987) con el número 3 de su tipología, fue también denominada «Forma afim da Dressel 30» en las producciones de Porto dos Cacos (Raposo, 1990) y, posteriormente, variante A de la Almagro $51 \mathrm{C}$ en las alfarerías del Valle del Sado (Mayet y Silva, 1998; 2002).

Es una forma inspirada en los modelos galos de fondo plano, caracterizada por un cuerpo ovoide o piriforme, que termina en un pie anular (Fabião, 1998: 186). Borde desarrollado como una banda lisa al exterior, sección subrectangular o subtriangular, vertical o arqueada, a veces con una o más ranuras en la cara externa; asas de cinta, con una o más ranuras longitudinales en el dorso y con un perfil arqueado o semicircular, que comienzan justo debajo del borde, generalmente en contacto con la parte inferior del mismo, y descansan sobre un hombro ancho y redondeado (Diogo, 1987: 184; Raposo, 1990: 126; Mayet y Silva, 1998: 122).

Los contextos más antiguos donde se documenta la Lusitana 3 parecen documentarse a principios del siglo II d. C., no siendo posible, por ahora, remontar a fines de la centuria precedente el inicio de su producción, que se habría prolongado hasta mediados del siglo III (Fabião, 2008; Mayet y Silva, 2016; Quaresma y Raposo, 2016).

En el Valle del Tajo, la producción está atestiguada en las alfarerías de Porto dos Cacos (Raposo, 1990; 2017), Quinta do Rouxinol (Duarte, 1990; Duarte y Raposo, 1996; Raposo, 2017) y, posiblemente, Garrocheira (Amaro y Gonçalves, 2016). En el Valle del Sado se produjo en las alfarerías de Pinheiro (Mayet y Silva, 1998), Abul (Mayet y Silva, 2002), Enchurrasqueira y, posiblemente, Quinta da Alegria (Fabião, 2008; Quaresma y Raposo, 2016) (Fig. 6).

Aunque se consideran normalmente ánforas vinarias, todavía faltan evidencias directas para demostrarlo. A favor de un contenido de este tipo, se suelen señalar sus características morfológicas y su similitud con la Gauloise 4, así como la no coincidencia cronológica con la periodización de las ánforas de salazones lusitanas (Diogo, 1987: 184; Fabião, 1998: 185-186; 2008: 735). Por el contrario, partiendo del presupuesto de que este tipo corresponde a una primera etapa evolutiva de Almagro 51C, otros autores defienden un contenido de conservas de pescado (Mayet y Silva, 1998: 122; 2002: 177).

Su difusión en el actual territorio portugués se puede considerar relativamente discreta. Está bien representada en el Bajo Tajo y en la península de Lisboa y, en menor medida, en el valle del Sado y en el interior de Alentejo. Aparece esporádicamente en el Algarve, la costa de Alentejo y Extremadura, así como en Mérida (Almeida y Sánchez Hidalgo, 2013: 50; Almeida, 2016: 207) y, posiblemente, en Idanha-a-Velha (Banha, 2006: gráfico 1). Aunque es abundante en Lisboa y absolutamente dominante en villa Cardílio (Fig. 8) -donde representa alrededor del 69,9\% del conjunto anfórico (Diogo y Monteiro, 1999: 203) - la Lusitana 3 no está especialmente representada en algunos de los otros centros de consumo donde se documenta.

Teniendo en cuenta que se produjo en cantidades considerables en las alfarerías del Tajo y del Sado, es muy sorprendente su baja presencia en términos cuantitativos en la mayoría de estos conjuntos. Igualmente sorprendente es su aparente ausencia en varios centros de consumo de Lusitania, tanto en el interior del territorio como en la franja costera. El escenario es especialmente desolador en el noroeste hispano, donde no parece estar documentada.

Sin embargo, se documenta en el sur y sudeste de la península ibérica en Punta del Moral, Ayamonte (Bombico, 2016: 363), Italica (Vázquez Paz, 2012: 261, fig. 2; García Vargas, 2016: 287), Munígua (Fabião, 2006: 106-107), Sevilla (García Vargas, 2015: 398; 


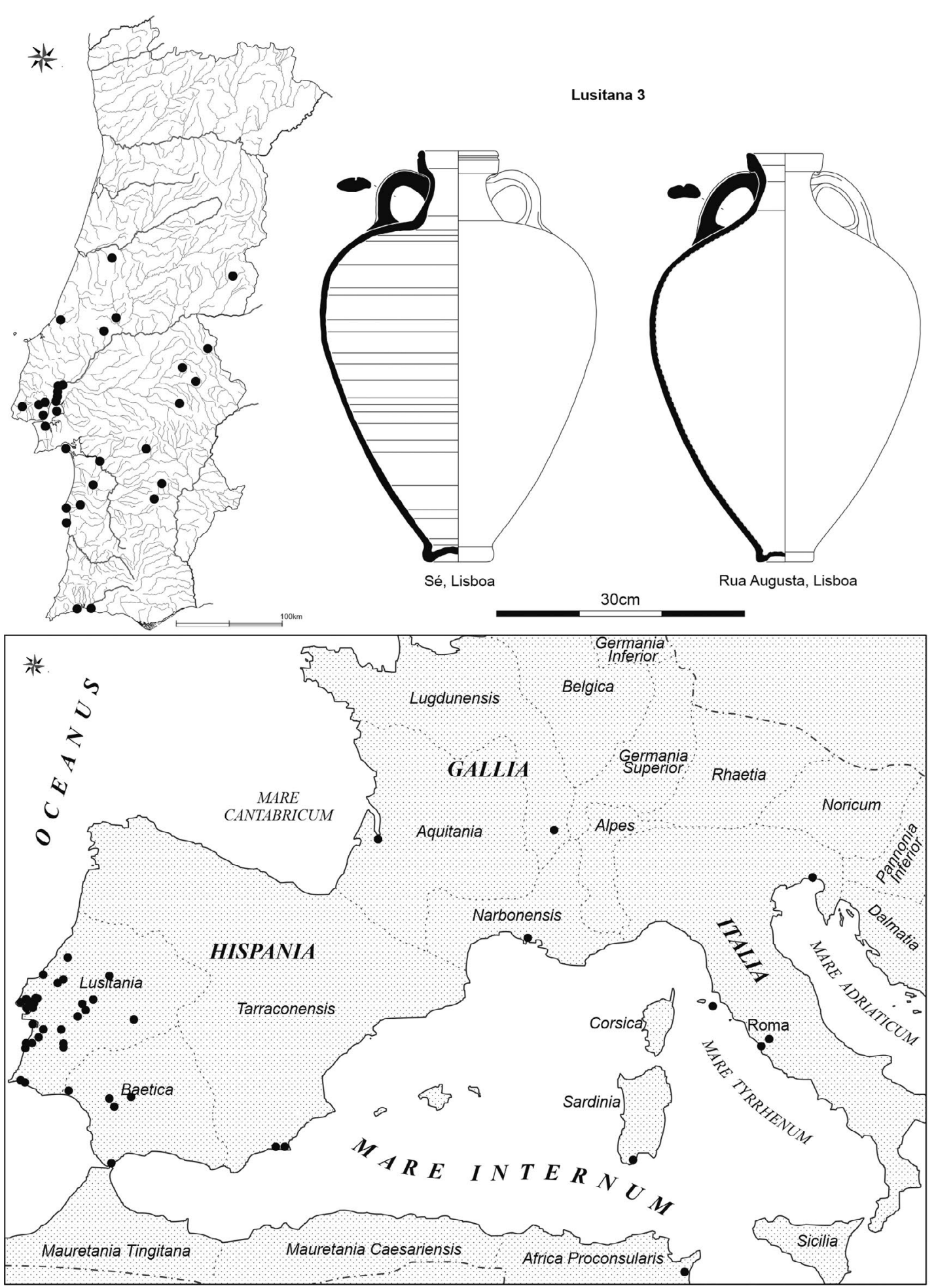

Figura 6: Ejemplares completos de Lusitana 3 y difusión del tipo en el territorio portugués y en el Mediterráneo occidental

2016: 288-294), Carteia (Bernal Casasola, 2001: 267; 2011: 11-12; 2016: 301), villa de Portmán (Bombico, 2016: 363) y Puerto de Mazarrón, Cartagena (Quevedo Sanchéz y Bombico, 2016: 315).

Más allá de los límites geográficos de Hispania, la Lusitana 3 está presente en Aquileia, en el Adriático (Gaddi y Degrassi, 2016: 439), Roma (Bombico, 2016: 247), muy probablemente en Ostia (Palma y Panella,
1968: 101 y tav. XXVIII, fig. 460), Cerdeña (Bombico, 2016: tab. 25), en la necrópolis tunecina de Pupput (Bonifay, 2004: 150, n. ${ }^{\circ}$ 16), en el naufragio del ArlesRhône 7 (Long y Duperron, 2011: 45, fig. 13, n. ${ }^{\circ}$ 1; Long y Duperron, 2013: 138, fig. 22, n. ${ }^{\circ} 1$ y 2), Arles (Quaresma, 2018: 204), Lyon (Bombico, 2016: tab. 25) y, posiblemente, Burdeos (Laubenheimer y Watier, 1991: 14, fig. 15). 


\section{LA PRODUCCIÓN DE ÁNFORAS EN LOS VALLES DE LOS RÍOS TAJO Y SADO Y EL CO- MERCIO DE VINO LUSITANO ENTRE FINALES DE LA REPÚBLICA Y MEDIADOS DEL SIGLO III}

La relevancia que ha adquirido la explotación de los recursos marinos en el estudio de la economía de Lusitania, que ha sido uno de los principales focos de atención de los investigadores, ha desviado, en cierta medida, la atención de otros importantes campos de investigación. A ello ha contribuido también, además de la visibilidad y proliferación de esas industrias, el hecho de que en las alfarerías conocidas está documentada principalmente la producción de ánforas de salazón de pescado, así como que estas son habitualmente mayoritarias en los centros de consumo, tanto en Lusitania como en otras provincias.

En este análisis de los datos disponibles, me centraré principalmente en las ánforas de las regiones productoras de los valles de los ríos Tajo y Sado, ya que es precisamente en estas zonas donde se produjo la inmensa mayoría de los contenedores de vino lusitano que conocemos hoy en día. De hecho, aunque la fabricación de imitaciones de Haltern 70 está documentada en Peniche, Mérida y en un lugar indeterminado del Algarve, lo cierto es que sólo las del primer lugar citado parecen haber logrado cierta difusión (y, aun así, en porcentajes muy inferiores a los del Tajo y el Sado), mientras que las de los otros dos centros productivos señalados sólo se documentan localmente.

De las morfologías descritas más arriba, la Haltern 70 corresponde al envase de vino más temprano de los fabricados en el Occidente peninsular, estando atestiguado desde el tercer cuarto del siglo I a. C. Surge en un momento en el que ya se había producido un fuerte descenso en la importación de vinos itálicos - escenario ampliamente documentado en toda la provincia de Ulterior (Mateo Corredor, 2016; Filipe, 2019) - y en el que dominaban los del Valle del Guadalquivir, envasados en las Ovoide 4 y Haltern 70. La imitación lusitana de esta última forma aparece, en esta etapa, en proporciones muy discretas, adquiriendo mayor representación durante el principado de Augusto. Hasta este momento, se atestigua principalmente en los sitios que forman parte del proceso de romanización y articulación del interior del territorio o donde hay presencia militar, coincidiendo con los circuitos de distribución de los productos béticos de la segunda mitad del siglo I a. C. (García Vargas et al., 2011: 265). Pero es la primera mitad del siglo siguiente la que resulta testigo del apogeo de la Haltern 70 lusitana, un tipo que podría haber sido producido hasta la época Flavia.

Es muy probable que el inicio de la producción de las imitaciones lusitanas de las ánforas de tipo Urceus remonte a un momento tardío del principado de Augusto, o al comienzo del de Tiberio, perdurando, al menos, hasta mediados del siglo I d. C.. Por otra parte, a pesar de la insuficiencia de datos relativos a la cronología de las imitaciones locales de Dressel $2-4$, es presumible que su producción también se enmarcase principalmente en ese siglo, extendiéndose posiblemente hasta el siglo siguiente. Así, se observa la contemporaneidad de la producción y comercialización de estas tres ánforas vinarias durante gran parte del siglo I d. C., siendo la Haltern 70 la más exitosa. A estos contenedores hay que añadir la «Dressel 28» lusitana, si se puede demostrar que su producción se inició en este siglo, lo que hay que reconocer que es bastante probable.

Estos datos indican una creciente y gradual representación del vino local/regional en los centros de consumo de Lusitania entre el tercer cuarto del siglo I a. C. y mediados del siglo siguiente, especialmente visible en la ciudad de Olisipo (Filipe, 2019). Sin embargo, no existe una situación similar a la observada con las salazones de pescado locales/regionales, que superaron en importancia en estos mismos centros a los productos béticos al final del principado de Augusto o al principio del de Tiberio (Filipe, 2020: 198). Es decir, que, a pesar de la creciente presencia de los productos locales/regionales, el vino bético fue durante todo este período siempre abrumadoramente dominante. Aun así, durante la primera mitad del siglo I d. C., el vino de Lusitania representaba aproximadamente el 10\% del consumo en la ciudad de Olisipo, una proporción cercana a la de los vinos importados del Mediterráneo Oriental y de la costa tirrénica de Italia y sólo inferior a la de la Bética.

Aunque estas proporciones pueden parecer modestas, y significativamente inferiores a las que se observarán en el siglo II d. C., la producción de vino en los valles de los ríos Tajo y Sado en el siglo I d. C. habrá alcanzado un volumen suficiente para justificar su exportación, como lo demuestra la presencia de la Haltern 70 lusitana en Arles (Djaoui y Quaresma, 2016; Quaresma, 2018) y en el noroeste peninsular (Morais, 2004; Morais y Fabião, 2007). Esto muestra un incremento considerable en la producción de vino, con repercusiones indudables en la economía local.

Este cuadro de consumo, que coincidió con un pico en el perfil global de las importaciones de alimentos transportados en ánforas (Filipe, 2018: 95), cambiaría drásticamente a partir del final del principado de Nerón o el comienzo de la dinastía Flavia. Se produjo entonces una caída significativa y generalizada del consumo de vino transportado en esos contenedores, en particular de los que se importaban desde el Valle del Guadalquivir. Aunque esta disminución también va acompañada de una disminución general de la importación de aceite de oliva, es más evidente en los productos de la uva, marcando el fin de la hegemonía del vino bético en Lusitania. Esto se puede ver principalmente en la baja representación de la variante flavia de la Haltern 70, pero también en la disminución general de otras morfologías vinarias (provinciales y extra-provinciales) en contextos del último tercio del siglo I d. C. (Filipe, 2019: 579). 
El acentuado desplome de las importaciones de vino sólo puede entenderse a la luz de la importante disminución del comercio de este producto que se produjo en la segunda mitad del siglo I d. C., lo que indica la afirmación de la viticultura local y regional, fenómeno que parece ser transversal a otras regiones del Imperio (Tchernia, 1986: 292; Fabião, 1998: 169). Sin embargo, entre las ánforas vinarias lusitanas del siglo I d. C. (Haltern 70, Urceus, Dressel 2-4 y, probablemente, «Dressel 28»), ninguna parece haberse producido en cantidad suficiente como para llenar ese vacío en el consumo de la apreciada bebida.

Por otra parte, es poco probable que la Lusitana 3 haya surgido antes de principios del siglo II d. C., solo alcanzando una producción realmente significativa a partir del segundo cuarto/mediados de ese siglo, dados los datos contextuales conocidos. En la ciudad de Olisipo, la mayoría de los ejemplares de este tipo recogidos en contextos romanos provienen de niveles fechados entre mediados del siglo II d. C. y mediados del siglo III, siendo raros en los niveles anteriores (Filipe, 2019). Esta realidad también puede observarse en la mayoría de los centros de consumo donde se documenta la Lusitana 3 (Fabião, 2008; García Vargas, 2016; Quaresma y Raposo, 2016).

La escasez de ánforas vinarias en niveles flavios difícilmente puede representar una disminución paralela del consumo de vino. Debe más bien constituir un indicador no sólo del aumento de su producción a nivel local/regional, sino también del uso preferente de otros tipos de contenedores para su transporte, en particular odres y/o toneles. Por consiguiente, debe considerarse la posibilidad de un aumento apreciable de la producción local/regional de vino a partir del final de la dinastía Julio-Claudia, que habrá compensado la reducción de las importaciones extraprovinciales. De hecho, otros autores han asociado ya la rareza de las ánforas de vino lusitanas con el uso de los toneles en la comercialización del vino local/regional (Brun, 1997: 56), aunque por motivos no específicamente relacionados con esta caída general del consumo de vino en el último tercio del siglo I d. C. Un razonamiento similar al nuestro se ha planteado para la región nororiental de la Tarraconense, donde la abrupta caída de las Dressel 3-2 desde finales del siglo I d. C. contrasta con la probada continuidad de la producción de vino en la región (Marlière, 2019: 74).

Aunque todavía no se han detectado vestigios materiales de odres o toneles en Lusitania -ya documentados en Hispania en Oiasso (Urteaga y Alkain, 2019) y Chaves (Costa Vaz et al., 2016)- hay algunas evidencias indirectas de su más que probable utilización, en particular la de los toneles. En primer lugar, la lápida de la tabernera Sentia Amarantis expuesta en el Museo de Mérida, extrayendo vino de un tonel con una jarra (Marlière, 2019). Por otro lado, y sobre todo, la representación de toneles en forma de monumentos funerarios (cupae), que conoció un notable uso principalmente en Alentejo (Fabião, 1998; Étienne y Mayet 2000; Pereira, 2017). Esta profusa representación de la cuba parece indicar su uso recurrente en la actividad vitivinícola en Lusitania. Cabe señalar que el uso de este contenedor para el transporte de vino, tanto terrestre como fluvial/marítimo, se habrá extendido por el Mediterráneo occidental a finales de siglo I d. C. (Brun, 2020: 12) y está bien documentado en varios lugares del Imperio (Marlière, 2019) (Fig. 7).

Esta asociación puede extenderse al segundo cuarto/ mediados del siglo II d. C., fecha esta última en la que, como se ha señalado supra, se inicia la producción a gran escala de las ánforas Lusitana 3. A partir de ese momento se hace difícil rastrear el uso de los toneles en el transporte de vino de Lusitania sobre la base de este tipo de argumentos, todo lo cual parece indicar que su uso ha disminuido desde entonces. Esta hipótesis es totalmente contraria, en el caso de Lusitania, a la idea de que la sustitución del ánfora por el tonel se habría producido en época Antonina (Tchernia, 1986). En cualquier caso, el uso a gran escala del tonel puede haber tomado un nuevo impulso desde mediados del siglo III d. C., cuando la producción de Lusitania 3 parece llegar a su fin y un nuevo recipiente de vino, la Lusitania 9, aparece muy tímidamente, siendo más representativo sólo desde mediados del siglo IV (Raposo y Quaresma, 2016). Las otras ánforas lusitanas tardías presumiblemente vinarias, Rouxinol 35 (Duarte,
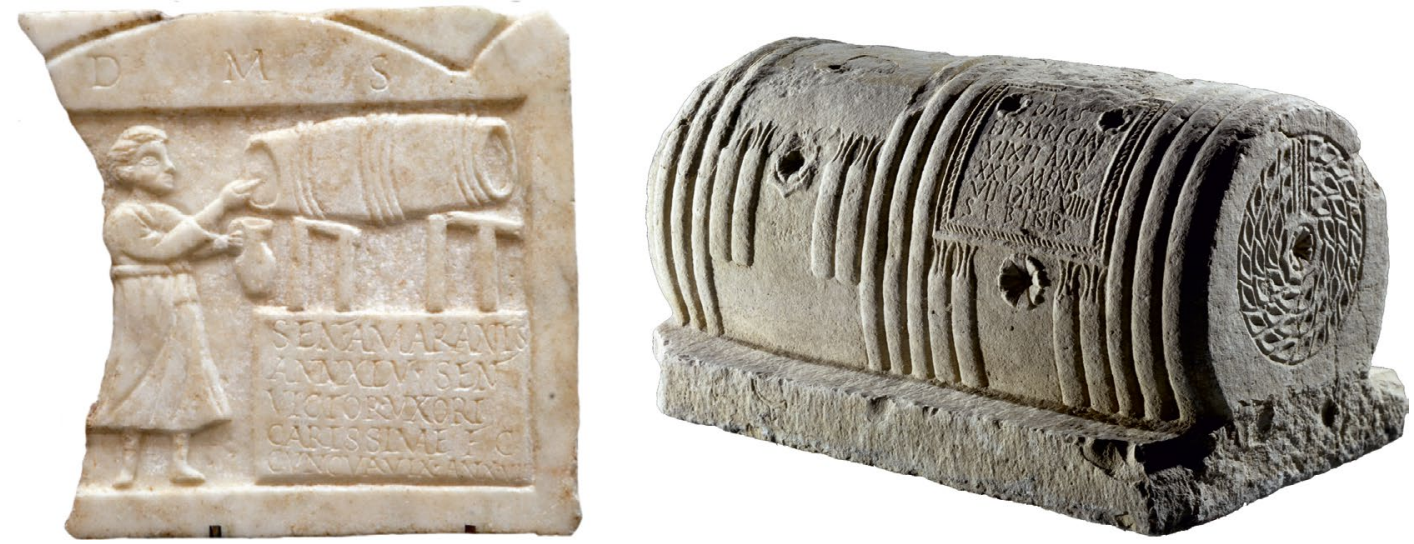

Figura 7: Lápida de la tabernera Sentia Amarantis (Museo de Mérida) y cupa de la Quinta de Marim (Museo Nacional de Arqueología) 


\begin{tabular}{|l|c|c|c|c|c|c|c|c|}
\hline & Olisipo & Scallabis & $\begin{array}{c}\text { villa } \\
\text { Cardílio }\end{array}$ & Salacia & Conimbriga & Mirobriga & Ammaia & $\begin{array}{c}\text { Augusta } \\
\text { Emerita }\end{array}$ \\
\hline Lusitania & $55,0 \%$ & $4,6 \%$ & $95,6 \%$ & $53,3 \%$ & $19,6 \%$ & $82,8 \%$ & $47 \%$ & $10,6 \%$ \\
\hline Baetica & $26,5 \%$ & $95,4 \%$ & $2,9 \%$ & $40,0 \%$ & $62,5 \%$ & $3,5 \%$ & $6 \%$ & $15,0 \%$ \\
\hline Tarraconensis & $2,6 \%$ & $0 \%$ & $0 \%$ & $0 \%$ & $7,1 \%$ & $0 \%$ & $0 \%$ & $7,1 \%$ \\
\hline Gallia & $6,3 \%$ & $0 \%$ & $0 \%$ & $6,7 \%$ & $5,4 \%$ & $6,9 \%$ & $18 \%$ & $10,6 \%$ \\
\hline Italia & $4,1 \%$ & $0 \%$ & $1,5 \%$ & $0 \%$ & $3,6 \%$ & $3,5 \%$ & $24 \%$ & $14,2 \%$ \\
\hline Norte de África & $0,5 \%$ & & & & & & & \\
\hline $\begin{array}{l}\text { Mediterráneo } \\
\text { oriental }\end{array}$ & $5,0 \%$ & $0 \%$ & $0 \%$ & $0 \%$ & $1,8 \%$ & $3,5 \%$ & $6 \%$ & $42,5 \%$ \\
\hline
\end{tabular}

Figura 8: Porcentajes de las diferentes zonas de procedencia del vino consumido en algunos sitios de Lusitania

1995) y Sado 4 (Pinto et al., 2012), nunca han alcanzado una representatividad significativa.

Volviendo a la Lusitana 3, esta es sin duda el ánfora de vino lusitana de mayor éxito, estando su producción documentada en grandes proporciones en los valles de los ríos Tajo y Sado. El reciente estudio de las ánforas de Olisipo (Filipe, 2019) ha demostrado la importancia que tuvo la Lusitana 3 en la distribución del vino lusitano, así como su preponderancia en el consumo local/regional, significando 55\% en el Alto-Imperio, pero alcanzando valores superiores al $75 \%$ si solo se considera el periodo entre los siglos II y la mitad del III. De hecho, en algunos de los conjuntos más representativos de la ciudad de Olisipo, como la Sé Catedral, Termas dos Cássios, Palácio dos Condes de Penafiel y Casa dos Bicos, la presencia de ese contenedor es incluso superior o similar a la del Dressel 14, que predomina principalmente en los sitios localizados en la zona «industrial» de la ciudad.

Estos datos revelan claramente la importancia de los productos regionales en el consumo de vino en Olisipo durante el principado, indicando también un incremento importante en Lusitania de la inversión en producción vinícola, lo que habría creado un excedente suficiente para posibilitar la exportación a otras provincias del Imperio. Su presencia en diferentes regiones del Mediterráneo central, desde el norte de África hasta Gallia, desde la costa adriática de Italia hasta la tirrénica y Cerdeña, pero sobre todo su expresiva representatividad en Munigua (Fabião, 2006: 106-107) y en Sevilla (García Vargas, 2015: 398; 2016: 294), revela una considerable difusión de ese contenedor lusitano, en contra de la idea de que sería un ánfora destinada meramente a la circulación regional. Cabe señalar también que, aunque hasta recientemente insospechada, esta geografía de distribución puede estar muy lejos de la real difusión que logró este tipo, quedando por comprobar sobre el volumen real de su exportación, ya que se trata de un contenedor con características que se confunden fácilmente con algunas categorías de cerámicas comunes, sobre todo cuando se trata de pequeños fragmentos.

Por todo lo expuesto anteriormente, parece que va siendo urgente reconsiderar la importancia de la vitivinicultura como uno de los principales motores económicos de las regiones de los valles de los ríos Tajo y Sado al menos desde el siglo II d. C. junto con la mejor conocida y estudiada explotación de los recursos marinos.

\section{CONCLUSIONES}

Teniendo en cuenta lo anterior, no cabe duda de que la producción de vino en Lusitania no estaba destinada únicamente al consumo local/regional. La documentación de ánforas vinarias lusitanas en varios lugares del Mediterráneo occidental es una buena demostración de su efectiva exportación a otras provincias del Imperio y de su integración en las redes de comercio marítimo de la época. Aunque hasta ahora las evidencias son escasas para la fase más antigua, la exportación de vino de los valles de los ríos Tajo y Sado habrá comenzado en la época de Augusto, atestiguada por la presencia de la Haltern 70 lusitana en contextos de esa época en el noroeste hispánico (Morais, 2004; Morais y Fabião, 2007). Su ocurrencia en el sur de la Galia (Quaresma, 2018: 202) amplía significativamente su alcance, constituyendo motivo suficiente para admitir que también pudo haber llegado a otros puertos mediterráneos durante los primeros tres cuartos de siglo I d. C. La amplia difusión de Lusitana 3 en la mitad occidental del Imperio atestigua el relativo éxito de los productos lusitanos en el gran comercio del vino, entre el segundo cuarto del siglo II d. C. y la mitad del siglo siguiente. Más difícil de rastrear será su eventual exportación en toneles, utilizados en el transporte del vino lusitano entre el último cuarto de siglo I d. C. y las primeras décadas del siglo II.

Sin embargo, el éxito del vinum Lusitanum se atestigua principalmente a nivel regional. Entre los centros de consumo, Olisipo y Mirobriga son los mejores ejemplos de ello, donde los productos locales/regionales alcanzan respectivamente el $55 \%$ y el $83 \%$ del consumo de vino durante el Alto Imperio. Por otra parte, villa Cardílio parece ser el mejor indicio de un lugar de producción y exportación de vino envasado en ánforas del tipo Lusitana 3, que representan el 96\% de los envases vinarios (Fig. 8). Este panorama refleja una importante inversión en vitivinicultura en los valles de 
los ríos Tajo y Sado al menos desde finales del segundo tercio del siglo I d. C., otorgando a esta actividad un peso significativo en la economía local.

La producción de vino y de ánforas vinarias en Lusitania sigue siendo un amplio campo abierto a la investigación, con muchas cuestiones aún sin respuesta. Es de suma importancia sistematizar los datos relativos a las estructuras de producción, así como estudiar y publicar la inmensa información de las excavaciones de los últimos 20 años, principalmente en el ámbito de la arqueología de urgencia. Otro campo de la investigación que será importante desarrollar se refiere a los estudios arqueométricos. En este caso, será especialmente importante obtener evidencias directas del contenido de las ánforas mediante la realización de análisis de residuos para confirmar o refutar el presunto contenido. Del mismo modo, sería importante revisar algunos conjuntos artefactuales, especialmente los procedentes de las intervenciones arqueológicas más antiguas, y valorar algunas de las tipologías vinarias lusitanas que a menudo no se identifican como tales. Por último, creo que una mirada más atenta y conocedora de los materiales de diversos centros de consumo del Mediterráneo occidental conducirá a la identificación de un mayor número de ánforas lusitanas y, en consecuencia, a una percepción más correcta de la representatividad del vino lusitano en las redes comerciales del Imperio.

\section{Agradecimientos}

Desearía agradecer a João Pimenta (Ayuntamiento de Vila Franca de Xira) la información inédita sobre los Urcei del Monte dos Castelinhos. A Enrique García Vargas (Universidad de Sevilla) le agradezco la revisión del español y los comentarios al texto.

\section{REFERENCIAS}

Alba Calzado, M. y Méndez Grande, G. (2005). Evidencias de industria paleolítica y de un alfar emeritense en Augusta Emerita. Intervención arqueológica realizada entre la prolongación de la calle Anas y el final de la Avenida Lusitania. Mérida, excavaciones arqueológicas 2002, 8, 375-409.

Almeida, R. R. (2016). On the way to Augusta Emerita. Historiographical Overview, old and new data on fish-product amphorae and commerce within the trade to the capital of Lusitania. En I. V. Pinto, R. R. Almeida y A. Martin (Eds.). Lusitanian Amphorae: Production and Distribution (pp. 195-218). Roman and Late Antique Mediterranean Pottery, 10. Oxford: Archaeopress. DOI: https://doi.org/10.2307/j. ctvxrq19c.19

Almeida, R. R. y Fabião, C. (2019). The 'early production' of Roman amphorae en Ulterior/Lusitania. State of play of a universe (still) under construction. En E. Garcia Vargas, R. R. Almeida, H. González Cesteros y A. M. Sáez Romero (Eds.). The ovoid Amphorae en the Central and
Western Mediterranean. Between the last two centuries of the Republic and the early days of the Roman Empire (pp. 175-190). Roman and Late Antique Mediterranean Pottery, 13. Oxford: Archaeopress. DOI: https://doi.org/10.2307/j. ctvpmw4m6.10

Almeida, R. R. y Sánchez Hidalgo, F. (2013). Las ánforas del Cuartel de Hernán Cortés. Nuevos datos para el estudio de la importación y consumo en Augusta Emerita. En D. Bernal, L. C. Juan, M. Bustamante, J. J. Díaz y A. M. Sáez (Eds.). Hornos, talleres y focos de producción alfarera en Hispania (pp. 49-58). Monografías Ex Officina Hispana, I, Vol. II. Cádiz: Universidad de Cádiz.

Amaro, C. y Gonçalves, C. (2016). The Roman Figlina at Garrocheira (Benavente, Portugal) in the Early Empire. En I. V. Pinto, R. R. Almeida y A. Martin (Eds.). Lusitanian Amphorae: Production and Distribution (pp. 47-58). Roman and Late Antique Mediterranean Pottery, 10. Oxford: Archaeopress. DOI: https://doi.org/10.2307/j.ctvxrq19c.6

Arruda, A. M., Viegas, C. y Bargão, P. (2006). Ânforas lusitanas da Alcáçova de Santarém. Setúbal Arqueológica, 13, 233-252.

Arruda, A. M. y Viegas, C. (2016). As ânforas alto-imperiais de Monte Molião. En R. Járrega Domínguez y P. Berni Millet (Eds.). Amphorae ex Hispania: paisajes de producción y consumo (pp. 446-463). Monografías Ex Officina Hispana, III, Vol. I. Tarragona: Institut Català d'Arqueologia Clàssica.

Banha, C. (2006). As ânforas romanas de Idanha-a-Velha (Civitas Igaeditanorum). (Trabajo fin de máster inédito). Faculdade de Letras da Universidade de Lisboa. Lisboa. Policopiado.

Bernal Casasola, D. (2001). La producción de ánforas en la Bética en el s. III y durante el Bajo Imperio romano. En Congreso Internacional Ex Baetica Amphorae. Conservas, aceite y vino de la Bética en el Imperio Romano (SevillaÉcija, 1998), Vol. I (pp. 239-372). Écija: Editorial Gráficas Sol.

Bernal Casasola, D. (2011). Vinos lusitanos del Porto dos Cacos en Carteia. Boletín Ex Officina Hispana, 3, 11-12.

Bernal Casasola, D. (2016). Lusitanian Amphorae in the Strait of Gibraltar: Interprovincial Food Supply. En I. V. Pinto, R. R. Almeida y A. Martin (Eds.). Lusitanian Amphorae: Production and Distribution (pp. 299-310). Roman and Late Antique Mediterranean Pottery, 10. Oxford: Archaeopress. DOI: https://doi.org/10.2307/j.ctvxrq19c.26

Berni Millet, P. (2011). Tipologia de la Haltern 70. En C. Carreras Monfort, R. Morais y E. González Fernández (Coords.). Ánforas romanas de Lugo Comercio romano en el Finis terrae (pp. 80-107). Trabalhos de Arqueoloxía, 3. Lugo: Concello de Lugo.

Bombico, S. (2016). Economia marítima da Lusitânia romana: exportação e circulação de bens alimentares. (Tesis doctoral). Universidade de Évora. Évora. Recuperado de: http://hdl.handle.net/10174/21051

Bonifay, M. (2004). Études sur la cerámique romaine tardive d'Afrique. BAR International Series, 1301. Oxford: Archaeopress. DOI: https://doi.org/10.30861/9781841716510 
Brun, J.-P. (1997). La production du vin et de l'huile en Lusitanie romaine. Conimbriga, 36, 45-72. DOI: https://doi. org/10.14195/1647-8657_36_3

Brun, J.-P. (2020). From Oil to Wine? A balanced view on the production of the most representative agricultural products of Antiquity. En J.-P. Brun, N. Garnier y G. Olcese (Eds.) Archaeology and Economy in the Ancient World. A. Making Wine in Western-Mediterranean; B. Production and the Trade of Amphorae: Some New Data from Italy. 19th International Congress of Classical Archaeology Cologne/Bonn, vol. 9 (pp. 3-21). Colonia-Bonn: Propylaeum.

Buraca, I. (2005). Civitas Conimbriga: Anforas romanas. (Trabajo fin de máster inédito). Faculdade de Letras da Universidade de Coimbra. Coimbra. Policopiado.

Bustamante Álvarez, M. y Cordero Ruiz, T. (2013). Une exportation viticole à Mérida? Considération sur la production locale d'amphores de style Haltern 70. En S. Celestino Pérez y J. Blánquez Pérez (Eds.). Patrimonio cultural de la vid y el vino (pp. 81-93). Madrid: Universidad Autonónoma de Madrid.

Bustamante Álvarez, M. y Heras Mora, F. J. (2013). Producción anfórica en Augusta Emerita (Mérida, Badajoz) y los nuevos hallazgos del solar de la Escuela de Hostelería. En D. Bernal, L. C. Juan, M. Bustamante, J. J. Díaz y A. M. Sáez (Eds.). Hornos, talleres y focos de producción alfarera en Hispania (pp. 331-345). Monografías Ex Officina Hispana, I, Vol. II. Cádiz: Universidad de Cádiz.

Bustamante Álvarez, M. y Heras Mora, F. J. (2016). Haltern 70 (Eastern Lusitania). Amphorae ex Hispania. Landscapes of production and consumption, 20 julio, 2016. Recuperado de: http://amphorae.icac.cat/amphora/ haltern-70-eastern-lusitania

Cardoso, G. (1986). Fornos de ânforas romanas na bacia do rio Sado: Pinheiro, Abúl e Bugio. Conimbriga, 25, 153-174. DOI: https://doi.org/10.14195/1647-8657 25 10

Cardoso, G. (1990). O forno de ânforas de Muge. En J. Alarcão y F. Mayet (Eds). Anforas Lusitanas, Tipologia, produção, comércio. Actas das Jornadas de estudo (Conimbriga, 1988) (pp. 153-165). Coimbra: Museu Monográfico de Conimbriga.

Cardoso, G. (2015). Estudio arqueológico de la villa romana de Freiria. (Tesis doctoral). Universidad de Extremadura. Badajoz. Recuperado de: http://dehesa.unex. es/handle/10662/3881

Cardoso, G., Rodrigues, S., Sepúlveda, E. y Ribeiro, I. (2016). Production during the Principate en Peniche (Portugal). Raw Materials, Kilns and Amphora Typology. En I. V. Pinto, R. R. Almeida y A. Martin (Eds.). Lusitanian Amphorae: Production and Distribution (pp. 3-17). Roman and Late Antique Mediterranean Pottery, 10. Oxford: Archaeopress. DOI: https://doi.org/10.2307/j.ctvxrq19c.4

Carreras Monfort, C. (2016). Haltern 70 (Baetica coast), Amphorae ex Hispania. Landscapes of production and consumption, 10 julio, 2016. Recuperado de: http://amphorae. icac.cat/amphora/haltern-70-baetica-coast

Cervantes, Y. P. (2020). Wine Making in the Iberian Peninsula during the Roman Period: Archaeology, Archaeobotany and
Biochemical Analysis. En J.-P. Brun, N. Garnier y G. Olcese (Eds.). Archaeology and Economy in the Ancient World. A. Making Wine in Western-Mediterranean; B. Production and the Trade of Amphorae: Some New Data from Italy. 19th International Congress of Classical Archaeology Colognel Bonn, vol. 9 (pp. 3-21). Köln - Bonn: Propylaeum.

Costa Vaz, F., Martín-Seijo, M., Carneiro, S. y Tereso, P. (2016). Waterlogged plant remains from the Roman healing spa of Aquae Flaviae (Chaves, Portugal): Utilitarian objects, timber, fruits and seeds. Quaternary International, 404 (A), 86-103. DOI: https://doi.org/10.1016/j.quaint.2015.09.063

Desbat, A. y Dangreaux, B. (1992). La distribuition des amphores dans la région Lyonaise. Étude de deux sites de comsommation. En Les amphores en Gaule, Production et circulation (Metz, 1990) (pp. 151-156). Paris: CNRS.

Dias, M. I., Trindade, M. J., Fabião, C., Sabrosa, A., Bugalhão, J., Raposo, J.,... y Prudêncio, M. I. (2012). Arqueometria e o estudo das ânforas lusitanas do Núcleo Arqueológico da Rua dos Correeiros (Lisboa) e de centros produtores do Tejo. Estudos Arqueológicos de Oeiras, 19, 57-70.

Diogo, A. M. D. (1987). Quadro tipológico das ânforas de fabrico lusitano. O Arqueólogo Português, Série IV, 5, 179-191.

Diogo, A. M. D. (1999). Ânforas romanas de Miróbriga. Arquivo de Beja, Série 3, 10, 15-27.

Diogo, A. M. D. (1999-2000). Ânforas romanas provenientes do nordeste alentejano (Herdade do Reguengo, Torre de Palma, Cabeço de Vaiamonte e Santa Vitória do Ameixial). Ibn Maruán, 9-10, 311-327.

Diogo, A. M. D. y Monteiro, A. N. (1999). Ânforas romanas de Villa Cardillio. Conimbriga, 38, 201-214. DOI: https:// doi.org/10.14195/1647-8657_38_8

Diogo, A. M. D. y Paixão, A. C. (2001). Ânforas de escavações no povoado industrial romano de Tróia, Setúbal. Revista Portuguesa de Arqueologia, 4(1), 117-140.

Diogo, A. M. D., Trindade, L. y Venâncio, R. (2005). Ânforas provenientes de achados subaquáticos ao largo da Berlenga. En Actas do Congresso A Presença Romana na Região Oeste (Bombarral, 2001) (pp. 109-117). Bombarral: Câmara Municipal do Bombarral.

Djaoui, D. y Quaresma, J. C. (2016). Lusitanian Amphorae from the Dump Layer above the Arles-Rhône 3 Shipwreck. En I. V. Pinto, R. R. Almeida y A. Martin (Eds.). Lusitanian Amphorae: Production and Distribution (pp. 357-368). Roman and Late Antique Mediterranean Pottery, 10. Oxford: Archaeopress. DOI: https://doi.org/10.2307/j.ctvxrq19c.31

Duarte, A. L. (1990). Quinta do Rouxinol. A produção de ânforas no Vale do Tejo. En J. Alarcão y F. Mayet (Eds.). Ânforas Lusitanas, Tipologia, produção, comércio. Actas das Jornadas de estudo (Conimbriga, 1988) (pp. 97-115). Coimbra: Museu Monográfico de Conimbriga.

Duarte, A. L. y Raposo, J. (1996). Elementos para a Caracterização das Produções Anfóricas da Quinta do Rouxinol (Corroios/Seixal). En $1{ }^{\circ}$ Congresso de arqueologia peninsular (Porto, 1993) (pp. 237-247). Actas VII, Trabalhos 
de Antropologia e Etnologia, 35, 3. Porto: Sociedade Portuguesa de Antropologia e Etnologia.

Ehmig, U. (2010). Dangstetten IV. Die Amphoren. Untersuchungen zur Belieferung einer Militäranlage in augusteischer Zeit und den Grundlagen archäologischer Interpretation von Fund und Befund. Forschungen und Berichte zur vor-und Frühgeschichte in Baden-Wurttemberg Band, 117. Stuttgart: Landesamt für Denkmalpflege im Regierungspräsidium.

Etienne, R. y Mayet, F. (2000). Le vin hispanique. Paris: De Boccard.

Fabião, C. (1998). O vinho na Lusitânia: reflexões em torno de um problema arqueológico. Revista Portuguesa de Arqueologia, 1(1), 169-198.

Fabião, C. (2006). Las ánforas romanas. En Munigua: la colina sagrada (pp. 106-107). Sevilla: Junta de Andalucía.

Fabião, C. (2008). Las ánforas de Lusitania. En D. Bernal Casasola y A. Ribera I Lacomba (Eds.). Cerámicas hispanorromanas. Un estado de la cuestión (pp. 725-745). Cádiz: Universidad de Cádiz.

Fabião, C., Guerra, A., Almeida, J., Almeida, R., Pimenta, J. y Filipe, V. (2016). Marcas de ânforas romanas na Lusitânia (do Museu Nacional de Arqueologia de Lisboa ao Museo Nacional de Arte Romano de Mérida). Corpus Internationale des Timbres Amphoriques, 19. Lisboa: Union Académique Internationale - Academia das Ciências de Lisboa - Centro de Arqueologia da Universidade de Lisboa (UNIARQ).

Filipe, V. (2008). Importação e exportação de produtos alimentares em Olisipo: as ânforas romanas da Rua dos Bacalhoeiros. Revista Portuguesa de Arqueologia, 11(2), 301-324.

Filipe, V. (2015). As ânforas do teatro romano de Olisipo (Lisboa, Portugal): campanhas 2001-2006. Spal, 24, 129-163. DOI: https://doi.org/10.12795/spal.2015i24.06

Filipe, V. (2016). Haltern 70 (Western Lusitania), Amphorae ex Hispania. Landscapes of production and consumption, 21 julio, 2016. Recuperado de: http://amphorae.icac.cat/ amphora/haltern-70-western-lusitania

Filipe, V. (2018). Consumption patterns on the edge of the Roman Empire: the import of amphorae in Olisipo (Lisbon, Portugal) between the 2nd century BC and the 2nd century AD. Rei Cretarice Romance Favtorvm Acta 45, 91-97.

Filipe, V. (2019). Olisipo, o grande porto romano da fachada atlântica. Economia e comércio entre a República e o principado. (Tesis doctoral). Faculdade de Letras da Universidade de Lisboa. Lisboa. Recuperado de: http://hdl.handle. net/10451/38619

Filipe, V. (2020). Las ánforas romanas más antiguas del occidente peninsular en Olisipo (Lisboa): contribución a su estudio. Spal, 29 (2), 179-204. DOI: https://doi.org/10.12795/ spal.2020.i29.23

Filipe, V. y Calado, M. (2007). Ocupação romana no Beco do Marquês de Angeja, Alfama: evidências de estruturas termais junto da porta nascente de Olisipo. Al-Madan, Série II, 15, Adenda electrónica IX, 1-10.

Gaddi, D. y Degrassi, V. (2016). Lusitanian Amphorae in Northern Adriatic Italy: the Eastern Part of Decima Regio. En I. V. Pinto, R. R. Almeida y A. Martin (Eds.). Lusitanian Amphorae: Production and Distribution (pp. 437-444). Roman and Late Antique Mediterranean Pottery, 10. Oxford: Archaeopress. DOI: https://doi.org/10.2307/j.ctvxrq19c.39

García Vargas, E. (2015). Ánforas vinarias de los contextos severianos del Patio de Banderas de Sevilla. En I. Aguilera Aragón, F. Beltrán Lloris, M. J. Dueñas Jiménez, C. Lomba Serrano y J. A. Paz Peralta (Eds.). De las ánforas al museo. Estudios dedicados a Miguel Beltrán Lloris (pp. 395-412). Zaragoza: Fundación Fernando el Católico.

García Vargas, E. (2016). Amphora Circulation in the Lower Guadalquivir Valley in the Mid Imperial Period: the Lusitana 3 Type. En I. V. Pinto, R. R. Almeida y A. Martin (Eds.). Lusitanian Amphorae: Production and Distribution (pp. 285-298). Roman and Late Antique Mediterranean Pottery, 10. Oxford: Archaeopress. DOI: https://doi.org/10.2307/j. ctvxrq19c.25

García Vargas, E., Almeida, R. R. y González Cesteros, H. (2011). Los tipos anfóricos del Guadalquivir en el marco de los envases hispanos del siglo I a. C. Un universo heterogéneo entre la imitación y la estandarización. Spal, 20, 185-283. DOI: https://doi.org/10.12795/spal.2011.i20.12

Laubenheimer, F. y Watier, B. (1991). Les amphores des Allées de Tourny à Bordeaux. Aquitania, IX, 5-39.

Long, L. y Duperron, G. (2011). Le mobilier de la fouille de l'épave romaine Arles-Rhône 7. Un navire fluvio-maritime du IIIe siècle de notre ère. En Société Française d'Étude de la Céramique Antique en Gaule, Actes du Congrès d'Arles (pp. 37-56). Marseille: Société Française d'Étude de la Céramique Antique en Gaule.

Long, L. y Duperron, G. (2013). Navigation et commerce dans le delta du Rhône: l'épave Arles-Rhône 14 (IIIe s. ap. J.-C.). En S. Mauné y G. Duperron (Dir.). Du Rhône aux Pyrénées. Aspects de la Vie Matérielle en Gaule Narbonnaise II (pp. 125-167). Collection Archéologie et Histoire Romaine, 25. Montagnac: Éd. Monique Mergoil.

Marlière, E. (2019). El odre y el tonel en época romana. Testimonios arqueológicos e iconográficos. En A. Morillo Cerdán, M. H. Hermanns y J. Salido Domínguez (Eds.). Ephemeral Archaeology, products and perishable materials in the archaeological record of Roman times (pp. 67-78). Mainz: Nünnerich-Asmus Verlag.

Mataloto, R., Williams, J. y Roque, C. (2016). Amphorae at the origins of Lusitania: transport pottery from western Hispania Ulterior In Alto Alentejo. En I. V. Pinto, R. R. Almeida y A. Martin (Eds.). Lusitanian Amphorae: Production and Distribution (pp. 139-151). Roman and Late Antique Mediterranean Pottery, 10. Oxford: Archaeopress. DOI: https://doi.org/10.2307/j.ctvxrq19c.15

Mateo Corredor, D. (2014). Comercio anfórico y relaciones mercantiles en Hispania Ulterior (ss. II a. C. - II d. C.). Instrumenta, 52. Barcelona: Universidad de Barcelona. 
Mayet, F. y Silva, C. T. (1998). L'atelier d'amphores de Pinheiro. Portugal. Paris: De Boccard.

Mayet, F. y Silva, C. T. (2002). L'atelier d'amphores d'Abul. Paris: De Boccard.

Mayet, F. y Silva, C. T. (2016). Roman Amphora Production In the Lower Sado Region. En I. V. Pinto, R. R. Almeida y A. Martin (Eds.). Lusitanian Amphorae: Production and Distribution (pp. 59-71). Roman and Late Antique Mediterranean Pottery, 10. Oxford: Archaeopress. DOI: https://doi.org/10.2307/j.ctvxrq19c.7

Morais, R. (2004). Problemàtiques i noves perspectives sobre les àmfores ovóides tardo-republicanes. Les àmfores ovoides de producció Lusitana. En Culip VIII i les àmfores Haltern 70 (pp. 36-40). Monografies del Casc, 5. Girona: Museu d'Arqueología de Catalunya, Centre d'Arqueología Subaquàtica de Catalunya.

Morais, R. (2005). Autarcia e Comércio em Bracara Augusta: contribuição para o estudo económico da cidade no período Alto-Imperial. Bracara Augusta. Escavações arqueológicas, 2. Braga: Unidade de Arqueologia da Universidade do Minho, Núcleo de Arqueologia da Universidade do Minho.

Morais, R. (2008). Novos dados sobre as ânforas vinárias béticas de tipo Urceus. Spal, 17, 267-280. DOI: https://doi. org/10.12795/spal.2008.i17.11

Morais, R. (2010). Ânforas. En J. Alarcão, P. Carvalho y A. Gonçalves (Coords.). Castelo da Lousa - Intervenções Arqueológicas de 1997 a 2002 (pp. 181-218). Studia Lusitana, 5. Mérida: Museo Nacional de Arte Romano.

Morais, R. y Fabião, C. (2007). Novas produções de fabrico lusitano: problemáticas e importância económica. En Actas del congreso Internacional CETARIAE. Salsas y salazones de pescado en Occidente durante la Antigüedad (pp. 127133). BAR International Series, 1686. Oxford: Archaeopress. Recuperado de: https://repositorio.ul.pt/handle/10451/10621

Palma, B. y Panella, C. (1968). Anfore. En A. Carandini, E. Fabbricotti, C. Gasparri, M. Tatti, M. Giannelli, M. P. Moriconi,... y A. Ricci (Eds.). Ostia I. Le terme del Nuotatore. Scavo dell'ambiente IV (pp. 97-116). Studi Miscellanei, 13. Roma: De Luca Editori.

Pereira, P. (2017). O vinho na Lusitânia. Porto: Edições Afrontamento. DOI: https://doi. org/10.21747/9789898351715/vin2017

Pimenta, J. (2017). Em torno dos mais antigos modelos de ânfora de produção lusitana. Os dados do monte dos castelinhos - Vila Franca de Xira. En C. Fabião, J. Raposo, A. Guerra y F. Silva (Eds.). Actas do Seminário Internacional e Ateliê de Arqueologia Experimental. A Olaria Romana (pp. 195-205). Lisboa: Centro de Arqueologia da Universidade de Lisboa (UNIARQ).

Pimenta, J., Ferreira, M. y Cabrita, A. C. (2016). The roman kilns at Estrada da Parvoíce, Alcácer do Sal (Portugal). En I. V. Pinto, R. R. Almeida y A. Martin (Eds.). Lusitanian Amphorae: Production and Distribution (pp. 73-79). Roman and Late Antique Mediterranean Pottery, 10. Oxford: Archaeopress. DOI: https://doi.org/10.2307/j.ctvxrq19c.8
Pimenta, J., Sepúlveda, E., Faria, J. C. y Ferreira, M. (2006). Cerâmicas romanas do lado ocidental do castelo de Alcácer do Sal, 4: ânforas de importação e de produção lusitana. Revista Portuguesa de Arqueologia, 9(2), 299-316.

Pinto, I. V., Magalhães, A. y Brum, P. (2012). Un dépotoir du Ve siècle dans l'officine de salaisons 1 de Tróia (Portugal). Rei Cretarice Romance Favtorvm Acta, 42, 396-406.

Pinto, I. V., Magalhães, A. y Cabedal, V. (2011). O complexo industrial de Tróia desde os tempos dos Cornelii Bocchi. En J. L. Cardoso y M. Almagro-Gorbea (Eds.). Lucius Cornelius Bocchus, escritor lusitano da idade de prata da literatura latina. Colóquio Internacional de Tróia (Tróia, 2010) (pp. 133-167). Lisboa - Madrid: Academia Portuguesa da Historia - Real Academia de la Historia.

Prudêncio, M. I., Dias, M. I. y Ponte, S. (2005). Amphorae in Sellium from the first century to the fifth century AD: importation and regional production. En M. I. Prudêncio, M. I. Dias y J. C. Waerenborgh (Eds.). Understanding people through their pottery. Proceedings of the 7th European Meeting on Ancient Ceramics (Lisbon, 2003) (pp. 201-209). Trabalhos de Arqueologia, 42. Lisboa: Instituto Português de Arqueologia.

Quaresma, J. C. (2005). Ânforas romanas provenientes da pesca de arrasto no Tejo, depositadas no Museu Municipal de Vila Franca de Xira. Revista Portuguesa de Arqueologia, $8(2), 403-428$.

Quaresma, J. C. (2018) Les amphores Lusitaniennes à Arles: quantification d'un procès de longue durée. En R. Járrega (Coord.). Estudios sobre ánforas hispanas (pp. 197-230). Tarragona: Ex Officina Hispana.

Quaresma, J. C. y Raposo, J. (2016). Lusitana 3 (Western Lusitania), Amphorae ex Hispania. Landscapes of production and consumption, 08 julio, 2016. Recuperado de: http:// amphorae.icac.cat/amphora/lusitana-3-western-lusitania

Quevedo Sanchéz, A. y Bombico, S. (2016). Lusitanian Amphorae in Carthago Nova (Cartagena, Spain): Distribution and Research Questions. En I. V. Pinto, R. R. Almeida y A. Martin (Eds.). Lusitanian Amphorae: Production and Distribution (pp. 311-322). Roman and Late Antique Mediterranean Pottery, 10. Oxford: Archaeopress. DOI: https://doi.org/10.2307/j.ctvxrq19c.27

Raposo, J. (1990). Porto dos Cacos: uma oficina de produção de ânforas romanas no Vale do Tejo. En J. Alarcão y F. Mayet (Eds). Anforas Lusitanas, Tipologia, produção, comércio. Actas das Jornadas de estudo (Conimbriga, 1988) (pp. 117151). Coimbra: Museu Monográfico de Conimbriga.

Raposo, J. (2017). As Olarias Romanas do Estuário do Tejo. Porto dos Cacos (Alcochete) e Quinta do Rouxinol (Seixal). En C. Fabião, J. Raposo, A. Guerra y F. Silva (Eds.). Actas do Seminário Internacional e Ateliê de Arqueologia Experimental. A Olaria Romana (pp. 113-138). Lisboa: Centro de Arqueologia da Universidade de Lisboa (UNIARQ).

Raposo, J. y Quaresma, J. C. (2016). Lusitana 9 (Western Lusitania), Amphorae ex Hispania. Landscapes of production and consumption, 08 julio, 2016. Recuperado de: http:// amphorae.icac.cat/amphora/lusitana-9-western-lusitania 
Tchernia, A. (1986). Le vin de l'Italie romaine. Essai d'histoire économique d'après les amphores. Paris: De Boccard. DOI: https://doi.org/10.3406/befar.1986.1221

Urteaga, M. y Alkain, P. (2019). Calzado, tejido y otras colecciones orgánicas en Oiasso (Irún). En A. Morillo Cerdán, M. H. Hermanns y J. Salido Domínguez (Eds.). Ephemeral Archaeology, products and perishable materials in the archaeological record of Roman times (pp. 263-280). Mainz: Nünnerich-Asmus Verlag.
Vázquez Paz, J. (2012). Cerámicas de importación africana en contextos italicenses de Bajo Imperio y la Antiguedad Tardia ( $2^{\mathrm{a}}$ mitad del s. III-inicios del VI d. C.). En J. Beltrán Fortes y S. Guzmán Sánchez (Coords.). La arqueología romana de la provincia de Sevilla, actualidad y perspectivas (pp. 255-272). Historia y Geografía, 183. Sevilla: Universidad de Sevilla.

Viegas, C. (2011). A ocupação romana do Algarve. Estudo do povoamento e economia do Algarve central e oriental no periodo romano. Estudos \& Memórias, 3. Lisboa: Centro de Arqueologia da Universidade de Lisboa (UNIARQ). 